\title{
The Phenomenology of Wine
}

The Architecture of Living Well

\author{
by \\ Keith Evans B.A., B.A.S
}

A thesis submitted to

The Faculty of Graduate and Postdoctoral Affairs

in partial fulfillment of the requirements

for the degree of

Master of Architecture

in

Architectural Studies

Carleton University,

Ottawa, Ontario

(C) 2012

Keith Evans 
Library and Archives

Canada

Published Heritage

Branch

395 Wellington Street

Ottawa ON K1A ON4

Canada
Bibliothèque et

Archives Canada

Direction du

Patrimoine de l'édition

395 , rue Wellington

Ottawa ON K1A ON4

Canada
Your file Votre référence

ISBN: 978-0-494-93523-1

Our file Notre référence

ISBN: 978-0-494-93523-1
NOTICE:

The author has granted a nonexclusive license allowing Library and Archives Canada to reproduce, publish, archive, preserve, conserve, communicate to the public by telecommunication or on the Internet, loan, distrbute and sell theses worldwide, for commercial or noncommercial purposes, in microform, paper, electronic and/or any other formats.

The author retains copyright ownership and moral rights in this thesis. Neither the thesis nor substantial extracts from it may be printed or otherwise reproduced without the author's permission.
AVIS:

L'auteur a accordé une licence non exclusive permettant à la Bibliothèque et Archives Canada de reproduire, publier, archiver, sauvegarder, conserver, transmettre au public par télécommunication ou par l'Internet, prêter, distribuer et vendre des thèses partout dans le monde, à des fins commerciales ou autres, sur support microforme, papier, électronique et/ou autres formats.

L'auteur conserve la propriété du droit d'auteur et des droits moraux qui protege cette thèse. $\mathrm{Ni}$ la thèse ni des extraits substantiels de celle-ci ne doivent être imprimés ou autrement reproduits sans son autorisation.
In compliance with the Canadian Privacy Act some supporting forms may have been removed from this thesis.

While these forms may be included in the document page count, their removal does not represent any loss of content from the thesis.
Conformément à la loi canadienne sur la protection de la vie privée, quelques formulaires secondaires ont été enlevés de cette thèse.

Bien que ces formulaires aient inclus dans la pagination, il n'y aura aucun contenu manquant. 
The Phenomenology of Wine

The Architecture of Living Well

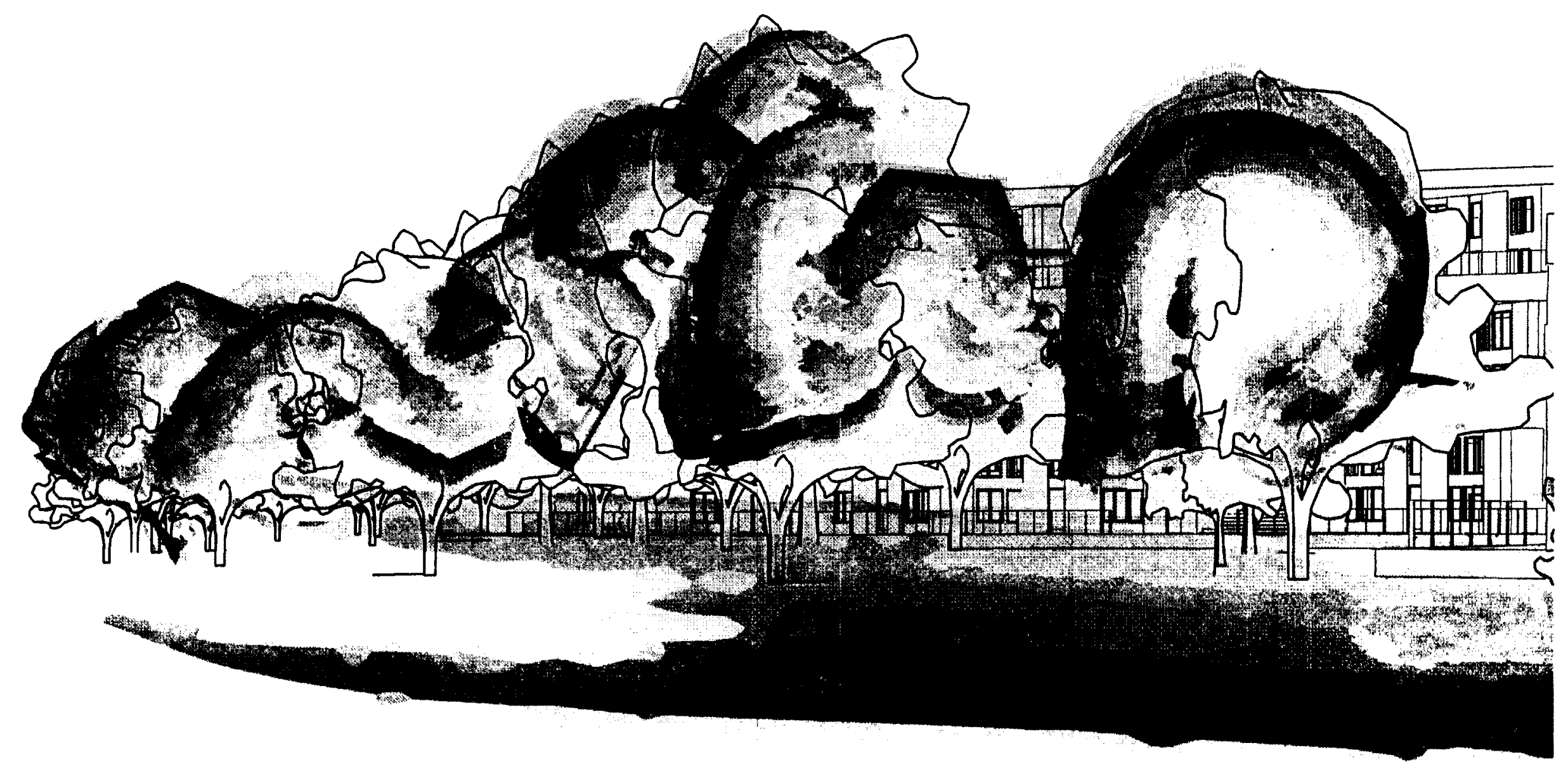


Abstract.

In todays environmentally conscience milieu there is a demand to live close to the downtown core where greater density is sought. The challenge is to provide a dwelling that meets the requirement for greater density, while providing a living space that evokes a sense of living well. In looking for a solution to this challenge this thesis looks outside of architecture to find inspiration in wine, which embodies the notion of living well. The experiential nature of wine, and its phenomena, brings to the wine drinker pleasure and happiness, which in turn reveals that when one is feeling happy they are enjoying life and thus living well. This thesis identifies the experiences and elements associated with wine to define a phenomenology of wine. Combined with the ideas of the 15 th century humanist Alvise Cornaro, who identified a means to construct architecture that can sustain a positive state of mind, a series of guidelines are defined that help inform design decisions for the proposed Riverside Garden, a multiunit residential building. The site for this proposed project is an undeveloped and challenging urban site located close to downtown Ottawa. This thesis uses these guidelines to explore a design for living well by establishing how issues of greater density and a challenging site can be overcome to create a residential building that will invoke and sustain happiness, thus allowing the dweller to live well. 
Table of Contents

Abstract.

List of images

Introduction

Chapter One A Phenomenology of Wine

A Disclaimer of Too Much Truth 3

Wine is an Art, the Elements of Wine

Wine is historic.

Wine lives well.

Wine is mysterious.

Wine needs tools.

Wine Experiences

Wine is better with company.

Wine is beautiful.

The Phenomenology of Wine

Chapter Two Sustenance of Happiness through Architecture

The Sustenance of Happiness within built form. 
Chapter Three Analysis and design guidelines for the Riverside Garden Site

Site Selection

Chapter Four Project Proposal

The Dwelling

Discussion

The Central Entrance

Terraces

Interior: hierarchy and delight

Exterior: materiality and massing

Tectonics

Conclusion

Images

Bibliography 


\section{List of images}

1460 Riverside Drive

Drawing 20B

Street View

Site Analysis One

Site Analysis Two

Riverside Garden

Axonometric

Figure 1

The Central Entrance

Figure 2

The Atrium Rear Entrance

Figure 3

The Atrium First Floor Plan

Figure 4

The Atrium Second Floor Plan

Figure 5

The Atrium Third Floor Plan

Figure 6

First Floor Plan

Figure 7

Second Floor Plan

Figure 8

Unit Floor Plan

Figure 9

Interior 
Figure 10

Exploded axio.

Figure 11

Longitudinal Sections

Figure 12

Section

69

Figure 13

Model

Figure 14

Elevation One

Figure 15

Elevation Two 


\section{Introduction}

This thesis investigates the challenge of redeveloping an undeveloped urban site located at the perimeter of downtown Ottawa. The site was previously farmland and then the entrance to one of the city's landfill sites during the 1960's. It is currently an unoccupied field. The physical location and adjacent features make the site challenging for redevelopment. This thesis seeks to test how the notion of living well can be extracted from what some people may see as a less then desirable site to live. The master plan of Ottawa encourages a greater density within the greenbelt. One issue of increasing density is the land available to do so is scarce. In many cases, existing structures are torn down to allow for new, taller, and denser residential buildings to be constructed. A vacant site offers a greater chance of developing a built form that can successfully provide privacy, intimacy, and comfort amidst close living quarters.

As we become more conscientious about our living space and how that affects the environment, there is an effort to provide dwellings which are more environmentally friendly, denser and, in many cases, smaller. Many present-day urban condominium buildings attempt to squeeze as much living space as possible out of ever-shrinking apartment footprints. As a result, design decisions are made that produce a livable product, but one that does not necessarily lend itself to, or enhance the notion of, living well.

There is still high demand for the advantages of suburban living - larger homes, large gardens, privacy, inexpensive buy in, to name a few. Given these urban pressures, how do we reconcile the continued demand for suburbia? What inspiration might architects draw upon that will provide the perceived advantages of suburban well-living in a dense urban environment? What does it mean to "live well" and how might this be achieved in the context of marginal urban infill sites?

For an answer to these questions we turn to wine - a model that represents living well. Through its production, but more particularly the social aspects associated with its consumption, wine has the ability to bring pleasure to all who enjoy it. For millennia, wine has been, and continues to be, an integral part of socialization. Nowhere is this truer than in Europe, especially Greece, where wine-making 
1 In chapter 9 of Paul Holberton's book Palladio's Villas (London, John Murray, Publishers: 1990). He discusses the meaning of the term villa. As in the case of the Rotonda, the term villa is ambiguous. The term villa can mean anything from a building, to an estate, to a lifestyle. Because of the ambiguity of the term villa, scholars such as

Holberton, Wirtkower, Boucher and others refer to Alemerico's house simply

as "the Rotunda." This treatment is

followed in this thesis. originated, and France where our present-day rituals associated with its consumption were defined. The pleasure-taking of wine stems from the long-established rituals and practices that surround not only the production, but more particularly the consumption of wine - the tools and materials of wine and the actions consumers of it go through when they are opening, sharing and sipping wine.

This thesis defines a phenomenology of wine. Based on the physical elements and properties of wine, and the experiences one has when drinking it, the phenomenology of wine establishes the basis of a notion of living well. Considered through the ideas of Alvise Cornaro, a 15th century humanist who identified that well-designed architecture can sustain the dwellers' positive state of mind, the phenomenology of wine reveals how architecture can both invoke and sustain happiness - or how architecture may allow us to live well.

The phenomenology of wine is then investigated as a built form. The Villa Rotonda ${ }^{1}$ is explored as historic built expression of the idea of living well. An examination of Andrea Palladio's Rotunda reveals how the phenomenology of wine can be invoked and sustained through design.

Through this examination, the thesis identifies the principles of "living well", and uses these to guide the design of Riverside Garden, a proposed multi-unit residential building. A challenging urban site is selected near downtown Ottawa. The selection of a difficult site is a deliberate one, as the opportunity of the idyllic location of the Rotonda is not easily come upon in today's economy and pressures towards increased density. The project proposal therefore tests the notion of living well within the urban challenge of living densely. The design exercise therefore seeks to create a built form where its dwellers may live well. 
2 Marco Frascari, Honestamente Bella, Alvise Cornarr's Anchitectural views of Lady Architecture and her Maids Phronesis and Sophrosine (Montreal: McGill University 2007) Presented at the "Reconciling Poetics and Ethics in Architecture" conference, McGill University, Sept 15, 2007. P 12
Chapter One defines the phenomenology of wine and discusses wine from a perspective of moderation. Wine cannot have anything to do with a good life if it is abused. However, wine in moderation its elements and the experiences associated with its consumption - can be associated with living well. Throughout the history of wine, as with today, challenges to moderation exist, but so too do the wonderful experiences that can happen with wine when it is consumed moderately. The history of wine is long and the elements that make up wine - where it is grown, how it is made and the materials and tools associated with it - have changed little in that time. Combined, these elements create an experience for the wine drinker, especially when sharing a glass with friends and family, that can be described as a moment that leads to living well. This thesis focuses on the experiential aspects identified with drinking wine - from the anticipation, to the tasting, to discussion with company, all of which are equally joyful. These aspects come together as the phenomenology of wine.

Chapter Two investigates how architecture can sustain the phenomenological experience of wine and translate that phenomenology into a built form. A successful example of the expression of wine through architecture is Palladio's Rotonda. As one of the last residences built by him, the Rotonda is arguably the culmination of his experience realized in an altogether new building in its time. The Rotonda also captures the idea of an architecture that sustains happiness, as developed by Alvise Cornaro, a mentor of Palladio. Cornaro developed his ideas in a treatise on architecture written in the early 1550 's. ${ }^{2}$ Cornaro's treatise is about sustaining one's pleasant state of mind through architecture and defines how architecture may be built to ensure the sustenance of the mind. By analyzing the Rotunda through the phenomenology of wine and Cornaro's ideas we see how that architecture can invoke and sustain a positive mental state.

Chapter Three explores the chosen site. An analysis is conducted on the site and presents the benefits of using this site for the proposed project. The history and geography are discussed. This chapter also explores the issues of density as they pertain to the selected site, as well as other available sites. While the first two chapters define the elements of living well, it is in Chapter 3 that these elements are applied to the site in order to define how this place may be built upon and landscaped to meet those ideals of 
living well. This chapter also explores how an intervention on this site may also benefit those who live in proximity to the site and for Ottawa as a whole.

The final chapter introduces the design proposal for the Riverside Garden, a multi-unit residential building, which draws on the defined elements of living well: a building conceived within architecture; a design that is grounded in history; the notion of living in moderation; a delight in mystery; the importance of being in a garden; and a selection of materials that may inform the design. Using these elements to inform the design decisions, the overall building is conceived as an alternative to suburban living. In this time of environmental awareness, the proposed edifice utilizes quality materials that will provide for a long-lasting building and a family home that affords greater density on the land it occupies. A blending of the ideas influenced from wine, Cornaro, and Palladio with contemporary issues of density, and most importantly the sustenance of happiness, result in a building where joyful living may occur, allowing the dwellers to live well. 


\title{
Chapter One
}

\section{A Phenomenology of Wine}

\author{
In Vino Veritas \\ Latin for "In wine there is truth"
}

Phenomenology is a philosophy and one that is closely associated with architecture. It relies on the elements of the building to create an experience one has while visiting or dwelling in the building. Phenomenology was developed by German thinker Edmund Husserl, who sought to develop a method of inquiry based on the body and not on science. Husserl initially sought to develop a way to experience and account for the essence of things, prior to when the mind begins to understand and categorize it.

1 Martin Heidegger, "Building Dwelling, Thinking," Rethinking Architecture. Ed. Neal Leach, (New York: Rutledge, 1997) p 107

2 Harry F. Mallgrave and David Goodman, An Introduction to Archisectural Theory. (West Sussex, UK: Wiley \&Sons, 2011) p211

Students of Husserl, notably Martin Heidegger, expanded on Husserl's work. Through a series of writings and essays, most notably "Building Dwelling, Thinking" Heidegger separates the act of dwelling as we commonly know it, that is to live somewhere, and writes that to truly dwell we must be thinking of that place: "The relationship between man and space is none other than dwelling, strictly thought and spoken."

Dwelling is our thought about our relation to space. Heidegger's thoughts were elaborated by more contemporary writers such as Christian Norberg-Schultz, Kenneth Frampton and Alberto PerezGomez, as well as practicing architects Steven Holl and Juhani Pallasmaa. It is the 1994 work of Holl, Perez-Gomez and Pallasmaa, published in an edition of the Japanese journal $\mathrm{A}+\mathrm{U}$, that bought the ideas of phenomenology to the mainstream of architectural thought. ${ }^{2}$ In that and later works, Holl and Pallasmaa outline the essence of phenomenology of architecture. For these architects and theorists, architecture's meaning is seated in the embodied experience of buildings. The forces of that experience are found in the site, notably the historical memories of the site, and the materiality and structure of the building. Materiality and structure compel the senses of touch, smell and sight. The sense of sight is specifically evoked through the use of light and shadow. These elements 
3 Steve Holl, Intertwining. (New York: Princeton Architectural Press, 1996) p 16 combine to create a holistic architecture that emphasizes perception and cognition. As Holl writes in his later work Intertwining: "Our aim is to realize space with strong phenomenal properties which elevates architecture to a level of thought."

The architect therefore creates a building that, through the elements discussed above, invokes an experience. The experience is not initially understood by the dweller or the visitor. However, once that brief experience happens, the mind then categorizes it and induces a thought process. Through the design, the architecture causes the dweller to think of their surroundings. It is through one's senses that one can experience the phenomenology of architecture. Through the site, the design of the built form, its materials and tectonics, contribute to create an experience for the body and allow the dweller to think about their relationship to that space. It is the experience of the architecture, and the essence of that experience that is the phenomenology of architecture.

The phenomenology of wine identifies the experiences and the elements that contribute to the experiences when enjoying a glass of wine. While the perception that wine is associated with the good life is not a new one, an architecture that is based on the phenomenological experiences of wine might be. Unlike a design of a building that is based on an architect such as Holl's ideas of the phenomenology of architecture that invoke an experience, here we seek to take the elements that make up the phenomenology of wine and apply them to a built form, such that the architecture of that building will invoke the same pleasurable experiences that wine does. By taking the essences of the phenomenology of wine into the design process of a building, that phenomenology informs us of how to design for living well. The following are the elements and experiences of wine, the pieces that are necessary to come together to establish a phenomenology of wine. By understanding these elements and experiences, we will more effectively incorporate the notion of living well into an architectural strategy of urban intensification. 


\section{A Disclaimer of Too Much Truth}

4 Rod Phillips, A Short History of Wine. (Toronto: Penguin Books, 2000) p55

5 Phillips, p57

6 Luigi Cornaro, The Art of Living Long (New York: Arno Press, 1979) p. 94, cited in Marco Frascari. p 24
In discussing wine as a phenomenological example of living well, the discussion must pertain to moderation. It would be appropriate initially - that is prior to examining the essences and experiences of wine that describes living well - to express that moderation is key. Throughout history there have been examples of the pleasures of the vine and the displeasure of it.

The history of wine points to many examples of societal norms of acceptable behaviour when it comes to wine consumption. For example, in the early Hellenistic period (c.300BCE), the Greeks believed that not getting drunk was a sign of civility. Those who drank enough to get to the truth during symposia (from the Greek word symposion, meaning drinking together), without becoming drunk, were considered the epitome of Greek society. There was, of course, substantial class division then. When someone of high social status and wealth got drunk, it may have been a lapse that "might be considered a necessary implication of a civilized and finely regulated occasion." $\mathrm{On}$ the other hand, a distinction was made between that person and someone of lesser standing who, when they became drunk, were seen as deplorable and unable to control their consumption.

Even in those early times, efforts were made to promote moderation. The Spartans, for example, demanded it. Once a year, the Spartan elders would provide unlimited wine to their slaves and let them drink openly while forcing the Spartan youth to watch the intoxicated slaves behave badly; the intent being to scare sobriety into the youth. ${ }^{5}$

Ideas of moderation continued into the 16th century. In his Treatise on a Sober Life (1558), Venetian humanist Alvise Cornaro (1484 - 1566) cautioned drinkers to keep wine consumption to only two glasses a day; else one would ruin its "restorative and spiritual powers."

A more contemporary and positive example of consuming wine in moderation is the parties of socialites Sara and Gerald Murphy. The Murphy's, American expatriates who lived in France from 1921 to 1934, were central to the expat community, befriending the likes of Cole Porter, Ernest 
7 Calvin Tomkins, Living Well is the Best Revenge. (New York: the Viking press 1962) p32

8 Tomkins $\mathrm{p} 33$
Hemingway, John Dos Passos, the Fitzgerald family (the life of the protagonist in F. Scott's novel Tender is the Night is based on the lives of the Murphy's), Pablo Picasso and Igor Stravinsky, to name a few. Their parties were always major events and rarely did the festivities get out of hand. One event in particular is worth noting. Gerald, a known painter, painted the backgrounds for the production of Stravinsky's play Les Noces, which was performed by Sergei Diaghilev's Ballets Russes ballet company. The Murphy's organized a celebration to be held on a barge in the Seine River on the opening night of the play, that Sunday night. It turned out that the flower shops were closed that day, so the Murphy's bought bags of cheap toys, such as small fire engines, cars and dolls to decorate the table. They created little pyramids of the toys along the table instead of flowers. When Picasso arrived, he collected a quantity of the toys and over the course of the evening and with only a little wine, worked the toys into a "fantastic 'accident,' topped by a cow perched on a fireman's ladder." ' In this particular event "no one really got drunk, no one went home much before dawn, and no one in all probability, has ever forgotten the party."8 With wine in moderation, good memorable things can happen.

\section{Wine is an Art, the Elements of Wine}

The viticulture of wine is a science, but more so, the oenology of wine is an art form. It is art because it requires judgment and experience, and because it improves and evolves with that experience. It is a science because there are formulas and techniques which require exactitude and precision, replication and control.

This thesis focuses on wine as an art form. Understanding the elements that comprise the art of wine - its production and consumption - will allow us to identify the elements needed to master the art of living well.

\section{Wine is historic}

The first element is history. History grounds us. When something is new and of history there is a comfort we feel. Even though something may be new, or something we have not experienced, if we 
9 Phillips pl

10 Phillips $\mathrm{p} 32$

11 Franck Ferrand, ed. Bondeaux Chateaux: A History of the Grands Crus Classes 18552005 (Paris: Flammarion 2004) p.74

12 Phylloxera is a tiny aphid that would attack the roots of the vines. Over time it would lay thousands of eggs and the young would consume the roots thus killing the vine. It is suggested that it spread from American vines that had the aphids but were tolerant of them. By the beginning of the 20th century most vines in Europe were replanted grafted onto American rootstock.

Phillips, p281-287 are familiar with its history then we know it. Someone may be trying a new type of wine, a grape they have never had before, or perhaps a wine from a country or producer they have never tried. But they know wine, and the trepidation or anxiousness that comes with trying something new or being in unfamiliar surroundings is not present in the testing of a new wine. In this case, it is a new wine, but we know wine. It has history, and we are familiar with it.

Wine benefits a long history. There has never been a time, from the Neolithic period to the present and even during the temperance movement, when wine was not consumed by all strata of society. In the Zagros Mountains, in Iran, evidence exists that as early as $7500 \mathrm{BCE}$, during the Neolithic period, juice was stored in clay jars and allowed to naturally ferment before being drunk.9 The Greeks were the first society known to develop the idea of viticulture. Around $500 \mathrm{BCE}$ they were planting and maintaining vines, and were exporting their wine and knowledge of viticulture to their colonies. ${ }^{10}$ During this early time, it was already acknowledged that wine was an element of pleasure, in the broad sense, but that it was not a necessity of life.

The wine consumed by the Greeks at the height of their pre-Common Era civilization, as well as that consumed by the Romans at the peak of their empire, was much different than what we consume today. It is supposed that in that time, wines were sweeter, heavier and consumed diluted with water.

There is, however, at least one wine that is available that is not dissimilar to the wines available almost 500 years ago. At the beginning of the 16th century, the winery of Haut-Brion, now Chateau Haut-Brion, just outside of Bordeaux, France, began to produce a high quality wine from what is now known as the Cabernet Sauvignon grape. ${ }^{11}$ This wine is still available today. However, the present version is not from the same rootstock and vines of the original, owing to the phylloxera crisis in the late 19 th century. ${ }^{12}$ A wine drinker trying a Chateau Haut-Brion Cabernet Sauvignon for the first time will likely experience the joy of its newness - having never tasted it before, but will also feel a sense of comfort and history, knowing that they are partaking in the rituals of a long standing tradition. 
13 Cornelis van Leeuwen, "An Exceptional Terrior" Bordeaux Chateaux: A History of the Grands Crus Classes 1855-2005 ed. Ferrand, Franck.(Paris, Flammarion 2004) p.24
14 Bacchus in the Villa of Mysteries (Pompeii) has been suggested to be 2 kind, protective spirit watching over the well being of the family of the villa, the household and its landholdings, then a deity of worship.

Molly Swetnam-Burland "Bacchus/Liber in Pompeii: A Religious Context for the Villa of the Mysteries Frieze;" The Villa of the Mysteries in Pompeii. Ancient Ritual Modern Muse. Gazda, Elaine K, ed. (Ann Arbor: University of Michigan Museum of Art, 2000) , p64.

\section{Wine lives well}

It starts in a terroir that is tended, managed and has history. Terroir ${ }^{13}$ is the French term that describes all the elements that go into making good wine; notably, the soil, the sun, the location of the vines, but also the history of the land. Wine starts on the vine that has been grafted on rootstock whose roots reach deep into the land. It spends its days in lush greenery, tended by vintners, warmed by the sun and cooled in the evening by its neighbours and their shade. Wine is the centre of attention. In its formative stage as grapes it is delicately tended for, well-fed and allowed to become firm and plump. When ripe, wine grapes are gingerly plucked off its vine and gently squeezed to release the goodness within. The goodness of the grape, and the juice that becomes the wine, receives its initial characteristics from the terroir. No matter how brilliant the vintner, a poor terroir will result in poor wine.

Wine becomes itself through a quiet process of change. Cultivated yeasts are added, which slowly convert the delicious sweet juice of the grape into alcohol. If the skins of the grape are included in the conversion, the wine will be red, and depending on the grape it may be dry. While the terroir imbues a multitude of flavours into wine, its final journey in white oak barrels, intensifies these flavours to deliver a unique viticultural identity.

\section{Wine is mysterious}

Only a few will know wine's real self. Before making its way to the bottle, wine will be tasted by only one, who - like a wine god figure such as Bacchus, watching over and protecting the sleeping wine ${ }^{14}$ - will decide what other wine will be mixed in, the proportion of the blend and when it will be bottled. Once bottled, wine will remain mysterious until served. Even then, wine will only expose itself slowly, wanting to tease the drinker as it reacts to the release from the bottle, its flavour ever-changing as it breathes and opens up, creating a different experience with every sip. The experience of that sip, especially of a well-crafted wine, will invoke happiness. The body, when sipping that wine, is enjoying the unveiling of the mystery, while the mind is experiencing the glory of the wine itself. This oenological experience adds depth and richness to our lives. 
15 Phillips p44.

16 Phillips p137

\section{Wine needs tools}

Once the vintner has blended the science and art into the craft of making the best wine they can make, they leave it up to the consumer to decide if they have succeeded. To do so - to experience wine - a variety of implements are needed. Historically, the experience of the wine itself was confined to one sense - taste. Wine was drunk from large open clay bowls, which the Greeks called kantharos - a large double handled drinking cup, which in many instances were highly decorated. The wine consumers of that time did not concern themselves with the presentation, aroma and feel of the wine. After all, it was often diluted with sea water. ${ }^{15}$ Since the birth of inexpensive glass, wine containers changed from large clay vessels to glass bottles. Upon the realization that cork was a perfect medium to seal a glass bottle of wine, the implements of wine also changed. As bottles began to be made with long narrow necks, it ensured that the cork fit snugly into the glass. Thus a corkscrew, originally called a bottlescrew, ${ }^{16}$ was created.

The birth of inexpensive glass-making allowed wine glasses to complete their evolution from clay bowls to metal challises to glass wine glasses. Over time, the aroma of wine grew in importance, as a method to gauge its character. The wine glass was modified to suit specific types of wine. A stemmed wine glass - its overall shape a holdover from the chalice - is still used with the belief that holding the glass by its stem will not affect the temperature of the wine from the heat of one's hands. This is especially true for white wines. Attached to the stem is the bowl, the shape of which denotes the type of wine it would hold. A very large bowl with a narrow opening is used for lighter wines like a Pinot Noir, whose aroma is more delicate than that of a Syrah or Cabernet Sauvignon. Bolder wines, whose aroma are more pronounced and do not need as much volume to express its bouquet, can be poured into a smaller wider opening glass. White wine, normally served cool, only has a hint of aroma, and is experienced primarily through taste. Thus a white wine glass often has a very broad opening, but not as broad as a champagne glass, where the experience is purely taste-related. 
White wine has additional implements, which are used to keep it cool, such as a clay sleeve. The sleeve is held in cold water for a short period of time and when the wine is being served, the bottle is kept in the sleeve except when the wine is being poured. The insulation properties of the clay, even as the sleeve dries out over the period of wine consumption, will keep the wine a few degrees cooler than room temperature. These tools and the elements described here are all for the benefit of the wine consumer whose ultimate aim is to open the bottle of wine and experience the joys of its contents.

\section{Wine Experiences}

There is a relationship between happiness and a good life. When you are happy, in that happy time, life is good, and when life is good you are living well. A good experience can summon happiness, and if one is in an environment which can sustain the sense derived from that experience, then happiness can be prolonged. As Cornaro stated, sustaining happiness “... is based on his understanding that happiness quickly fades away without the presence of the assimilated consciousness that has produced it and that architecture can help to maintain it by fostering a vita beata: a good life." 17 In other words, if the thing that created the happiness ends, such as finishing a bottle of wine, the architecture must be pleasant enough to sustain that happiness. Cornaro suggests that well-thought, well-built architecture will assimilate the consciousness and prolong the happy experience. In this case, happiness is experiential - a phenomena - of which there are many with wine. The following are a phenomenology of wine, the experiences that one may have with wine, which are based on the above- described elements.

Culturally, wine and the experiences it fosters, embodies the notion of living well. The experiences are based on what was noted earlier, moderation. And specifically the beneficial outcomes of the positive experience a person or a group of people may have when enjoying a glass or two of wine. This enjoyment comes across all levels of society and cultures. The many experiences of consuming wine - from anticipation of the taste, the excitement when looking at the bottle and 
extracting information from the label, a discussion of the potential goodness inside, to when the cork finally comes out and the wine's aroma confirms the contents to be of quality - form the basis of a phenomenology of wine. And so, it is worth exploring these experiences in more detail.

When poured, after allowing the wine to breathe or immediately, wine suddenly becomes very personal. All senses are activated while the wine is examined visually: does the colour agree with the type; if it is a big bold wine is the colour robust? What of its structure, does it have legs? The film that clings to the glass as the wine is swirled and settles back into the bowl of the glass indicate a lot or little alcohol. The swirling opens up the wine, and allows its aroma to be more thoroughly expressed. The sense of smell is experienced when the bowl is brought up to the drinker's nose and deeply inhaled. Images of fragrant fruit are captured and then further explored when the first sip is taken. There is an interval when that first sip has been taken, a moment before all the flavours of the wine begin to register, when the true experience of the wine happens. Wonderful things are always used to describe the taste of good wine: fruit, chocolate, hints of oak, honey and pepper.

In many cultures, sharing a glass of wine is an important component of socialization. The expressions on the face of guests is always pleasant: smiles, grins, perhaps a thoughtful pause while still experiencing the taste and smell, and then another grin and a smile. Then, the oratorical takes over, as verbal descriptions of the experience, spontaneous expressions and reactions are offered, and more thoughtful comments lead to a delightful discussion.

The discussion of wine enhances its contribution to living well. Wine is a social experience. With family over dinner, or with friends after work, wine is a focal point. Among discussion of the day's happenings, the wine may be described while it is being un-corked, smelt, tasted and then discussed. As the wine is drunk there is still conversation expressing its qualities, how it has opened up, how it is exhibiting new flavours, how the aftertaste has changed, and how the fruit has mellowed and the oak has increased. 
18 Phillips p 54

19 Gail Bronson, "In Advertising, Big Names Mean Big Money." U.S. News o World Report, vol. 95 n.1, (1983) p48

\section{Wine is better with company}

As mentioned in the introduction, symposium was an event where Greek men would come together to talk and discuss. The wine was seen as the lubrication for the truth. ${ }^{18}$ In contemporary culture, when someone is upset and wishes to drown their sorrows, it is rare that the libation of choice is wine. In film and television, for example, it is rare that someone is seen at the bar doing shots of a 10 year old Pinot Noir. In our contemporary cultural milieu, the glass of wine is associated with the more pleasurable pursuits of life: a couple over dinner, a dinner party or a social gathering. The cultural representation of wine is important. It indeed promotes the good life and living well. When Orson Wells declared of Paul Masson's wine on television commercials in the late 1970's "we will sell no wine before its time," he did so in situations where the wine was associated with pursuits of happy social engagements. ${ }^{19}$

The social experience of wine is even better when associated with the hierarchy of wine. The hierarchy of wine ranges from drinkable to a superb or very fine wine. A gathering of neighbours may bring out a nice, but usual bottle of wine. However, for special guests, a dinner party, or on very special occasions, a better wine will always impress and it is at these special occasions that a finer wine should be served. The server would not want to be boastful about his/her selection, even though a nicer wine creates the sense of being special. Sometimes, it is the act of being invited into the host's inner sanctum - which might be a physical place, but more importantly a symbolic one - that creates the important feeling of being special. To share with someone something that is not normally shared is to express cultural and social acceptance. Before the Common Era, the Greeks were a highly hierarchical society. Wine was no different. The best was kept for the male citizens to share only on special occasions. In fact, one's reputation was reinforced by the quality of the wine they served. A lesser wine was typically served to the women of the house, whereas the slaves got the dregs of the amphora mixed with water. ${ }^{20}$

This practice of saving the best wine for the best company has continued throughout history. In 1660 Arnaud de Pontac, the then-owner of Haut-Brion, made what was probably the first-known attempt to create a brand name in the wine industry. In an effort to increase the profit to his winery, 
21 Phillips p 142

22 Robert Coustet, "A History of Wine Architecture". Chateaux Bondeaux, ed. Jean Dethier,(London: Mitchell Beazley, 1989) P 66

23 Coustet p67

24 Cellared in Canada wines refers to inexpensive wines that come from a variety of foreign sources and are blended and bottled in Canada, they usually denote an inexpensive and low quality product.

Gordon Hamilton, "Consumers 'Deceived' by Low-cost Imports Being

Sold as B.C. Wines." The Vancouver Sun,

(Vancouver, B.C. Sept. 19, 2009) Section

$\mathrm{H}, \mathrm{pl}$ he named the wine that was produced from his own vineyards Haut-Brion. By singling out his own wine from the rest of the wine sold in England, he "created a premium wine which appealed to the status conscious London market."21 De Pontac was also the first vintner to build a specific building for his vineyards "as an outward sign of his ownership of the land"22 in the form of a manner house. When built, he called it a chateau and thus named his wine Chateau Haut-Brion, further establishing the status and hierarchy of his wine. ${ }^{23}$ This hierarchy continues today. For example, when serving one of the best Canadian wines ever produced, Mission Hill's 2005 Oculus will bring smiles of delight and anticipation when sharing such a special bottle. Those sharing it will feel a sense of closeness to the owner of the wine, a feeling that they are in a space that is less casual then someone may feel if they are being served a "Cellared in Canada" product. ${ }^{24}$

\section{Wine is beautiful}

We look at it in the glass, while swirling it around, and we look at the "legs" of the wine. The beauty is seen in its colour and of course its taste. But there is also the beauty of the wine from its origin, from the vine and terroir it is grown in. Experiencing a glass of wine in a vineyard is beyond that of a table, even in the most beautiful room.

Not only is the beauty of wine found in the drink and vine, but the garden it is grown in. There is a clear association of wine and the garden and living well. The lush green of the vines and the multitude of the colours of the grapes come together in the most beautiful garden. The smell of a vineyard is fragrant, especially as the growing season is at its peak, just as when a garden is in full bloom. While the vineyard is the basis of the start of the phenomenology of wine, the garden can encapsulate all the experiences that wine can create. It is in the garden that one may enjoy the company of friends, find solace as they retreat from their day-to-day lives and allow the freshness of the garden, its fragrant cool air, to assist in keeping one's thoughts sound and sustained. In their own words, the Murphy's lived well, but their living was even better when they moved to their renovated villa in the south of France. Sara Murphy stated: "the villa itself was a sort of chalet, small and 
25 Tomkins p 37

26 Tomkins p126 unpretentious, but the garden was extraordinary"25 They dined in the garden, and entertained and held memorable dinner parties in it. Gerald Murphy, in particular, was noted for saying that they lived well, but that they lived even better in their garden. ${ }^{26}$

\section{The Phenomenology of Wine}

Combined, the experiences associated with making, consuming and sharing wine, as well as the elements that define the character of wine, can be said to make up the phenomenology of wine. The long history of wine grounds us in the knowledge of what it is. Even at an early age, we know of wine. When sipping a glass of wine, especially if it is a new varietal or house, there is comfort and not the anxiety that comes from trying something never tried before. Part of the history of wine is found in the terroir, how long the land has been tended to produce that wine. However the terroir is also the soil, its location and its relation to the sun, it is the vineyard and the garden. With the tending of the terroir, good things grow. In the garden, not only do good things grow but good things happen, allowing the gardener, or the person strolling through it, to experience them.

These experiences never present themselves completely. There is always a sense of mystery that accompanies wine, and that unfolds when a bottle is selected and then opened and tasted. The hierarchy of wine emphasizes the mystery. A person may not always be able to afford or share an exceptional bottle of wine, and the anticipation when they do is heightened. The heightening of anticipation is increased when, in a gathering of friends or family, wine encourages social interaction. And the materiality of wine - clay, wood, copper, glass and its shape - can express the olfactory senses, while the other materials evoke a tactile and visual response. Phenomenology is about the experience of a place, and the things that occur in that place, including the material and character that define the sense of place. In the case of the experiences of wine, and the elements that create them, the phenomenology of wine does, in the best of ways, provoke a pleasant experience.

To summarize, we have seen that the elements of wine are history, taste, transformation over time, mystery, and the need for tools. The experience of wine can be characterized as living well: it is a 
personal as well as collective experience. Even when an inexpensive wine of low quality is served, the act of gathering around a bottle creates a sense of specialness. But it is even better when a special wine is served, as guests are invited both literally and metaphorically into a special place where a strong and unique experience is shared. This phenomenology tells us that living well is enhanced by the environment in which it takes place.

The following chapter investigates how architecture can invoke and sustain the phenomenological experience of wine. A significant example of a building that possesses the same qualities that make up the phenomenology of wine is Andrea Palladio's Rotunda (1567 - 1585?), a suburban residence located in the northern Italian town of Vicenza. We will see how the Rotunda resonates with the phenomenology of wine, and in particular how the architecture allows the owner to live well within it. 


\section{Chapter Two}

\section{Sustenance of Happiness through Architecture}

Having established the phenomenology of wine and identified Palladio's Rotonda as the building that resonates with it, it is also necessary to show how the Rotonda embodies the phenomenology of wine and is able to sustain happiness derived from the phenomenology of wine through its architecture. This chapter explores the application of the phenomenology of wine to that built form, and seeks to describe an approach to design that allows the dweller to live well. The approach is specifically informed by Alvise Cornaro's ideas of living well, and how those ideas can be captured and sustained within architecture, and its surrounding landscape. The approach suggests that when architecture succeeds in tangibly embodying an idea, in this case the phenomenology of wine, it can sustain that idea through time - that is, through the physical make up of the building. The dweller of that architecture can then be said to be living well.

\section{The Sustenance of Happiness within built form}

In Marco Frascari's article Honestamente Bella, Alvise Cornaro's Architectural View of Lady Architecture and Her Maids, Phronesis and Sophrosine, he argues that many architects today are not thinking in architecture but of architecture. This distinction is important because, as Frascari suggests, it results in architecture that fails to sustain a positive, happy state of the dwellers' mind. If a dweller experiences positive phenomena, such as sipping a good wine, and the space in which they sipping that wine is not an architecture created by thinking in architecture but rather of architecture, then the space will fail to provide the sustenance needed to prolong that positive experience. The dweller will not be able to live well in the building.

Frascari argues that contemporary architecture is being governed by thinking of architecture, mainly the financial decisions and personal design ideas instead of the pleasure of design that comes when the architect thinks within architecture. ${ }^{27}$ To remedy this situation and to produce an architecture that fulfills the dwellers' mental sustenance by prolonging positive happy experiences, which leads to living well, Frascari argues that architects must return to well-thought, well-built buildings. 
28 Frascari p9

29 Alvise Cornaro cited in Frascari pl0
Frascari points to the relationship between Cornaro and Antonio Averlino (1400 - 1469). Averlino, also known as Filarete (Greek for Lover of Intellectual Excellence/Virtue), was an architect whose treatise on architecture, Trattato di Architettura, 1461-1464, influenced Cornaro's thinking. Filarete is an example of an architect who thinks within architecture, and whose ideas centre on virtuous architecture. Filarete argued that architects who think within architecture begin the process of designing and building knowing that the virtues of their craft are essential components to making buildings that are well-thought and well-built. Filarete sees the virtues needed as:

...a duality of making and doing, virtues are undeniably essential components of any architectural facture. On the one hand, humility, magnanimity, integrity, fortitude, simplicity, and ingenuousness are the edifying virtues to be embodied in the architectural configurations; and on the other hand, prudence and temperance are the cardinal moral standards of architectural edification ${ }^{28}$

Filarete believed that the architect who pursued these virtues was working within architecture. If Filtrate's treatise promotes that architecture "sustains a beatific life,"29 the influence on Cornaro is also clear. Cornaro's treatise on long life and architecture also relies heavily on notions of virtue and temperance, and on sustaining one's happiness through architecture. As noted in Chapter One, Cornaro understands that happiness can quickly dissipate if there is no environment to sustain it. In order to sustain that happiness, architecture must then be well-thought and well-built, and also possess the tangible results of Cornaro's ideas on architecture.

\section{Alvise Cornaro on Happiness in Architecture}

Alvise Cornaro, a mentor of Palladio, developed the idea of sustaining happiness through architecture in his treatise: Trattato di architettura (c. 1550-53).$^{30}$ In addition to thinking within architecture, Cornaro asserted that an architect's idea alone is not enough. Rather, the architect must also work with the knowledge of materiality and history to develop and design the architecture. As well, there should be access to fresh air through a garden. Finally, the designs should be conceived for ordinary citizens. 
31 Frascari p30

32 Frascari p17

33 Frascari p14

34 Frascari 27

35 Frascari p16
Cornaro suggests that architecture is not an idea onto itself, but rather that the ideas of architecture emanate from the drawings as the tangible result of the architects thoughts. An architect must "happily meditate on the process" 31 , as they develop their ideas through the drawings. If the meditation is virtuous and enjoyable then the architecture will be well-thought and well-built, resulting in buildings that will sustain a happy state of mind.

When discussing ideas of architecture, Cornaro states: "architecture does not begin with an idea from which to generate a design, but begins with a set of materials out of which an idea is generated." 32 Cornaro sees the architect as a cook, the head chef as it were, who combines the chosen elements that will make the building in a fashion that will create a beautiful building that sustains the dwellers positive mental state.

Of history, "Cornaro's perception of architecture derives from history, but is not in itself historical." 33 As the building looks to the past and is healthy in the present, it allows for the mind and body to contemplate the future. In other words, the building itself is not historic; however the architect looks to the past and is aware of historic precedent when conceiving the design of the new building. The building is new, but grounded in history, allowing the dweller to be familiar with it.

The Architecture should also allow access to the cool fragrant air of a garden or surrounding landscape. This is an important element, since cool fresh air assists in the dwellers' mental health, which is itself an important ingredient in the sustenance of happiness. ${ }^{34}$

Cornaro suggests that architecture must not be monumental. Rather, it should be "infraordinary", that is neither ordinary (a bland structure built without thought or ideas) nor extra-ordinary, (a palace which only a few may be able to afford). It should be designed for citizens not princes. ${ }^{35}$ It can be said that Palladio would not fall into the ordinary camp since the monumental palaces he did design would fall mainly on the side of the extra-ordinary. However, as we will see with the Rotonda, he is capable of finding the space between the two, where he designed an "infraordinary" building. 
36 Robert Tavernor. Palladio and Palladianism. (London: Thames and Hudson, 1991) p19

37 Tavernor $\mathbf{p} 21$

38 Tavernor p22

39 Tavernor p29

40 Andrea Palladio, The Four Books of Architecture. Translated by Robert Tavernor and Richard Schofield. MIT press Cambridge Mass. 1997. Book II, xxi p95
Above all, a positive spirit and delight of the architect's mind will render good architecture, and in so doing it may sustain the dwellers' spirit, allowing them to live well. As much that Cornaro captures these elements in his writing, it is Palladio who captures them in his building.

\section{Cornaro's presence in the Rotonda}

Prior to Palladio's career in architecture, he apprenticed as a stone mason. Through introduction, Palladio met Gian Trissino (1478 - 1550), a Vicentine humanist and one of the greatest scholars of his time. ${ }^{36}$ Trissino, who was in Cornaro's circle, became a tutor and mentor of Palladio. ${ }^{37}$ The influence of both scholars, Comaro and Trissino, guided Palladio to the designs that he would eventually develop on his own. Both Cornaro and Trissino encouraged Palladio to copy the drawings of other architects and to sketch the ruins in Rome, all this in an effort for Palladio to express his own ideas through his drawings and work. ${ }^{38}$ Cornaro urged Palladio to make his own direct studies of antiquity and so discover the secrets of the ancients for himself. Palladio followed this advice, which allowed him to compete with the Roman exile architects in Vicenza at that time, and eventually win his first commissions. This early advice and subsequent years of experience culminate in the design of the Rotonda.

Palladio's design for the Rotonda reflects not only his own experience and knowledge, but clearly reflects Cornaro's views on architecture. The materials are of the site, and the building is of history, but it is not historic. The Rotonda is also not overly adorned with omament to be classical, ${ }^{39}$ as a direct copy of the Pantheon would be. We see in Palladio's work the notion of thinking within architecture, and how it captures both the phenomena of wine and the essences of Cornaro's ideas of sustaining those experiences, therefore allowing the dweller to live well.

\section{A Suburbano, not a villa}

Although the Rotonda is commonly referred to as a villa it is not. The original owner, Monsignor Paolo Almerico, considered it a suburbano - a suburban residence. Palladio initially referred to it as "his place on a hill,"40 "his" referring to Monsignor Almerico. It is worth noting that in his Quattro Libri Dell'Architettura (Four Books on Architecture), Palladio included the description of 
41 Palladio book II p45

42 Holberton p10S

43 Holberton $p 6$

44 Palladio, Book II, xxi p45 the Rotonda in Chapter III, Book II wherein he discusses houses in the city, not country houses. To Palladio it is a Dominus Hortus ${ }^{41}$ - a garden house. The term villa only came into common usage in the late 18th century when Palladio's Quattro Libri was translated into English by Charles Middleton. ${ }^{42}$ The Rotonda fell into the villa category due to the work undertaken by the Capra Brothers who purchased the property in 1591. With architect Vincento Scamozzi, the Capra's made numerous changes to the building, including the addition of outbuildings which were more common to the Villa Rustica tradition - that is, traditional Roman farming villas.

The common definition of villa, according to Middelton, is a large palatial property in the country. The ancient Roman definition - Villegiatura - means a cool airy house, visited occasionally for a break from the pressures and anxieties of life in town. ${ }^{43}$ However, these definitions do not apply to the Rotonda. This is not to say that Palladio does not incorporate some of the ideals of country life into the building, since he clearly understood the relationship of the ancient villa and living well: "... this is why the sensible men of the ancient world make a habit of withdrawing frequently to such places... where they could easily pursue a good life." ${ }^{\text {"4 }}$ It is not in the case of the Rotonda a "villa lifestyle" that Palladio was designing for. Rather, he designed a year-round residence, a home just outside of the town of Vicenza that sought to capture a lifestyle for Monsignor Alemerico, so that he may live well.

\section{Capturing the phenomenology of wine}

As the phenomenology of wine is ephemeral, we need to look at the Rotonda as the tangible example that translates the essence of the phenomenology of wine into a built form. This section explores the Rotonda and how it captures that essence. It will also explore how Palladio captured Cornaro's ideas of sustaining happiness through a built form. The following explores how the elements and experiences that make up the phenomenology of wine are expressed through the Rotonda. 
45 Bruce Boucher, Andrea Palladio, The Architecture in His Time. (New York: Abbeville Press 2007) p264

46 James A. Ackerman, The Villa. (London, Thames and Hudson: 1990) p50

47 Brenda Longfellow, "A Gendered Space? Location and Function of Room 5 in the Villa of the Mysteries." The Villa of the Mysteries in Pompeii. Ancient Ritual Modern Muse Gazda, Elaine K, ed. (Ann Arbor: University of Michigan Museum of Art, 2000) p26

48 Gazda. 66

\section{Grounded in history}

The Rotonda captures the essence of history, but it is not historic. The historical basis of the massing of the Rotonda is the Pantheon in Rome, which is a temple. Palladio captures the Pantheon but alters it by adding three additional loggias to the building, borrowing from the sacred and making it secular. ${ }^{45}$ Palladio thus created a new type of building for its time.

Also found in history is the use of a hierarchy of rooms. A historical example is found in another suburban residence, which is also presently referred to as a villa, the Villa of Mysteries. This suburban residence provides the historic basis of the interior definition of space, which includes a number of elements that are found in the Rotonda: a hierarchy of rooms, large social areas (public space), and a separation of public and private space. The Villa of the Mysteries is located just outside of the walls of Pompeii. Like the Rotonda, the Villa of the Mysteries is a suburban house. Unlike the Rotonda, it probably started as a Villa Rustica and over two centuries of building and rebuilding became a house where the owner lived year around. At the time of the eruption of Mount Vesuvius in $79 \mathrm{CE}$, the house was being altered to include a farming wing, ${ }^{46}$ just as 1,500 years later alterations were made to the Rotonda to add farming elements.

The most important room in the Villa of the Mysteries is Room 5. This room contains a fresco cycle, which has been interpreted in many ways, including a Bacchus cult offering assistance to women in marriage, procreation and promises of protection and bliss in the afterlife. ${ }^{47}$ Room 5 is an example of the use of hierarchy of rooms. It is a substantial distance from the entrance and public rooms, and as such a guest visiting Room 5 would have to be a special person in order to be invited to that space. As Brenda Longfellow discusses in her essay: A Gendered Space? Location and Function of Room 5 in the Villa of the Mysteries, the further the room from the entrance or a semi-public space within the home a guest is invited, the more known or special that guest would be to the homeowner. "In these old roman villas, the ability of the visitor to penetrate further into the private space depended on their social status and relationship to the owners of the house." room, the further away it is from the public spaces. 
49 Holberton p207

50 Frascari p16

51 Boucher p261
This notion is also found in the work of Palladio. In the case of the Rotonda, its grand hall or sala is central to the entrance of the building, and forms the Rotonda's central social space. The Rotonda was designed for entertaining, the sala, found under the rotunda is where friends and acquaintances would gather. Each quadrant leading off the sala leads to the more private living arrangements for the Monsignor and his guests. ${ }^{49}$ Although in the Rotonda, which is much smaller than the Villa of the Mysteries and the distance from the sala to the private rooms is less, the hierarchy of rooms, from public to private is clear; much like a good wine that you share with those you hold a closer relationship with than you would a casual acquaintance.

\section{In moderation}

In pleasant company, company for example the Monsignor was close to, a special bottle of wine may be served. In this environment, the bottle is special but because of the closeness of the company neither the wine nor the host is showing off, or being boastful. The special wine is a moderate selection for the company the Monsignor is hosting. The wine would elicit the anticipation of the guests while it is being prepared for serving. These qualities are found in Cornaro's ideas, wherein he identifies the importance of the impact that architecture should have on the inhabitant. However, while he agrees that architecture should have some monumentality expressed in its elements, he also states that the architecture should be "infraordinary": "infraordinary buildings' not 'extraordinary edifices,' I talk about rooms for citizens, not for princes." ${ }^{50}$ The Rotonda is special but "infraordinary". Like a special wine, it impresses the guests, but it does not boast. The Rotonda is moderate. Although a reasonably large building, in comparison to the city and country palaces that Palladio designed for his more well off clients, the Rotonda is a moderate sized house. In fact Almerico was hardly a prince, but was a Monsignor of adequate means, who to pay for his new house had to sell his city property. ${ }^{51}$ However, the Rotonda is not ordinary either. Its place is clear, it is on a hill, and visible from a distance. 


\section{In mystery}

Visitors would be impressed as they approached the Rotonda with its large porticos and stairs leading up to the entrance. Guests arriving at the Rotonda will have the privilege of waiting under the large portico for the Monsignor to arrive. The portico provides the guest shelter from the sun or the rain. If guests are known to the Monsignor, or have been invited, they will be brought through a narrow hall and into the sala, a sequence whose progression heightens the anticipation of what lies beyond. Moving from the large portico, through a door and into the hall, which is hiding but also hinting at what lays ahead, guests enter the sala. This sequence elicits a momentary pause, as one tries to comprehend what it is they are experiencing, much like that interval as the wine is sipped and all the flavours begin to register.

The large sala reaches up through the rotunda and what was once an oculus to the sky (the oculus has now been enclosed and the top of the Rotonda is a lantern). During the summer, the doors are open and the views from the sala reveal different gardens on each side of the building. The summer breeze captures the aromas of the gardens and carries these delicious aromas into the grand hall. The walls and ceiling of the sala are completed in frescos adding to the visual excitement of the guest. If the guest was staying, they may be taken from the sala to a more private room to dine or stay. ${ }^{52}$ However it is the sala that is central to the social experience of the Rotonda. Privileged guests who are invited in will feel that sense of happiness from the experience, and have it sustained as they feast their eyes on the frescos and architecture and the views of the surrounding landscape and gardens.

\section{The need of a garden}

Cornaro instructs in his treatise how to design a building so as to sustain a sense of happiness. In addition to the design of buildings, he also promotes the need of a garden. Palladio captures Cornaro's ideas in his design, but for the Rotonda relies on his experience from his Villegiatura designs, as described in chapter fourteen of the Quattro Libri. Here, Palladio discusses his most famous country houses, including the Villa Barbaro. It is in these designs that Palladio acknowledges the garden and its importance to living well. This experience is applied to the Rotonda, whose gardens and land is tiny by comparison to Villa Barbaro, this owing to there being 
53 Holberton p141

54 Holberton p127

55 Holberton p135

56 Palladio book II chap xii p45 no agricultural business on the site. The garden of the Rotonda is for the peace, tranquility and the recreation it may provide the Monsignor. The Monsignor would entertain his guests, for outdoor meals, entertainments such as plays and concerts and for walks and gardening.

As the Rotonda is surrounded by gardens, the four porticos offer views of them from the sala in all directions, and with it being built on a small hill, this enhances the views. The garden is as important to the Rotonda as it was to Palladio's other country houses and palaces. The garden is experiential in the values it brings the Monsignor, and his guests. Just as Cornaro identifies the need that architecture must allow for the dweller to make an investment in their emotional ability, he also knew the garden is a place to relax, look at views and recreate. Cornaro prescribed that the cool air with the smell of the garden "was a contribution to ... living long and well." 53 Palladio understood the importance of the garden and saw in it a pastime of looking out a window and having the "the landscape to show life around one." 54 Palladio also saw relaxation as a necessary component of good health. At a time when religion played a large part of everyday life, those who wanted to make their peace with God - apparently an arduous task - justified relaxation and recreation in the garden as an effort to remain mentally strong in order to be successful. ${ }^{55}$ In this way, the garden provides another aspect of living well, one which allowed the Monsignor and his guests the quiet repose to contemplate and rejuvenate. After the pleasures of wine, food and company one could find solace in the garden to reflect and regenerate..$^{36}$

\section{Materials as tools}

The garden or in this sense the site also provides for some of the materiality of the building. Cornaro wrote that one of the ideas of the architecture came from the materials chosen by the architect, that the architect was the "chef" choosing the ingredients for their creation. The materiality of the Rotonda was like many of Palladio's other houses: tactile, beautiful and inexpensive. Palladio - an original sustainable architect, if there ever was one - built with reeds from the site and plaster, as well wood and clay - which happen to also be the materiality of wine. The exterior of the Rotonda was not stone but clay brick with stucco covering it. Even the columns of the porticos and loggias are made of plaster covered brick. The properties of the clay and plaster allowed for a cool interior 
57 Frascari p24

58 James Ackerman, Palladios Villas. (Locust Valley, New York : JJ Augustin, 1967)p18

59 Boucher p265 in the hot Italian summer months, much as the way Cornaro prescribed the need for cool air to assist in keeping one's thoughts sound and sustained. ${ }^{57}$ Palladio's clients appreciated his ability to build grand buildings with inexpensive materials. Even when the client could afford stone they would, at Palladio's urging, stay with the less expensive clay and stucco. ${ }^{58}$ The use of these materials shows their lasting power. The Rotonda, although having undergone renovations to the upper floor to expand the living quarters, has not needed any form of structural make over: the brick, mortar and stucco have remained intact supporting the building structurally since its inception. It is reported that the only change is another coat of stucco on the exterior to freshen up the building from wear and tear. ${ }^{59}$

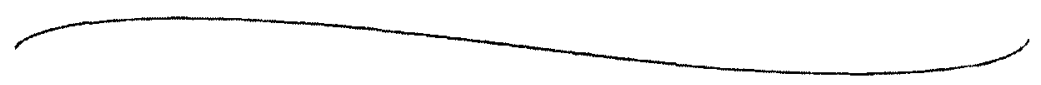

The Rotonda possesses both the qualities of the phenomenology of wine and Cornaro's idea of how architecture can sustain those experiences. By expressing the phenomenology of wine in its design and sustaining it, the Rotonda is able to present an architecture that evokes and sustains the good life without the need for the consumption of wine. The building and its landscape become the physical experience of the phenomena. As wine has history, so too does the Rotonda. However the Rotonda was not historic at the time it was built. The materials are familiar and some are local to the site, and help define the ideas of the building and the building's history but are used in a contemporary way for the sixteenth century. As with the uncorking of wine, the design of the Rotonda allows the building to reveal itself slowly; the mystery of the building unfolds as guests pass through the large external social spaces moving gradually into semi-public and eventually more private spaces. While the placement of the building on the site is such that to respond to that site, it also provides the dweller an opportunity to experience the beauty of the garden, just as a wine drinker may do on a picnic in a vineyard.

Palladio captures Cornaro's idea of designing the Rotonda in architecture, not of architecture. It is, as Cornaro outlined, a well-thought and well-built home, with the positive spirit and delight of the architect's mind, a quality needed in architecture so it may sustain the dwellers mind. Palladio 
60 Boucher p261

61 Boucher p265 clearly had this positive spirit and delight of mind when he designed the Rotonda. He created a new type of building for his client, one that is neither a palace nor a country estate, and such was his hesitation to call it one or the other in the Quattro Libri. His relationship with his client was excellent, one where they shared similar ideals, ${ }^{60}$ allowing him to have pleasure in the design. This has been clearly evident as the Rotonda has over time been elevated to the status of a classic. ${ }^{61}$

By looking at the Rotonda as a built form that resonates with the phenomena of wine and how Cornaro's ideas influenced Palladio, we have seen how Palladio's last great work not only captured the phenomenology of wine but, perhaps more importantly, how it is able to sustain it. In so doing, Palladio's architecture allows the dwellers of the Rotonda to live well, even to this day.

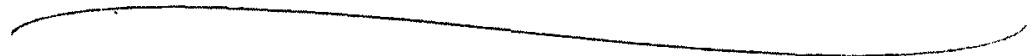

The following five design principles might be extracted from this account to suggest an approach to infilling an urban site in a way that invokes and sustains happiness in built form. The first is to design within architecture, not of architecture, which means to design with the positive spirit and delight of the architect's mind. The design would be meditated on and well thought out. The process of designing in a positive spirit while creating numerous drawings exploring the ideas will result in a well-thought and well-built building.

The design would be of history and yet not historic. Just as Palladio looked to the Pantheon as he designed the Rotonda, a contemporary building for its time, the proposed design for Riverside Gardens, will look to the Rotonda. The sense of history would allow both dwellers and guests to feel grounded in the architecture. Although the architecture may be new, they feel comfortable in it. The building would be situated in a garden, one that is large enough to be able to retreat to, stroll through, and to fill the dwellers' view from their windows and doors. The dweller should be able to tend to the garden if they want, but it should also be manageable. 
The building interior should contain an element of mystery. Rather than a single large room, where all is revealed at once, preference would be given to a series of rooms that suggest, without fully revealing, what is beyond them. This invites anticipation as the dweller or guest passes through the sequence of increasingly private spaces. In this way, guests will get a sense of moving from something that is casual or public, into a space that is reserved for the owners, and their special guests.

Since the social aspect of wine is an important part of the phenomenology of wine, there should be social gather places within the building which share that importance. The Rotonda possesses the sala, the central hall and the porticoes, all of which afford family, friends and guests the space within the building to gather and interact.

Finally, as Palladio chose the materials of the Rotonda, some of the site and others based on his experience as they informed his ideas, the materiality for the proposed building would also be based on materials appropriate to defining the experience of the building. Materials as seen in the phenomenology of wine - clay, glass, wood and metal - make the experience enjoyable and pleasurable. These materials may inform the design of a building so to create a visual and tactile response that make the experience of that place both special and unique.

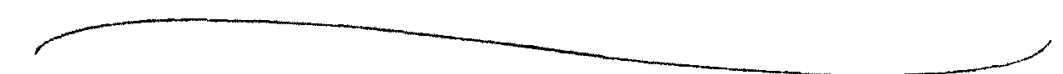

The following chapter explores how this approach to inducing happiness from the phenomenology of wine and sustaining it in a built form will become a series of guidelines for re-developing the chosen urban site. 


\section{Chapter Three}

\section{Analysis and design guidelines for the Riverside Garden Site}

This chapter describes a brief history of the chosen site for the proposed Riverside Garden project and proposes a re-development plan for that site. The historical account of the site provides the understanding of its present condition. It also identifies how the site, despite its challenges, is one of the few remaining undeveloped sites close to the downtown core that would support the elements defined in the previous chapters for the proposed design. This chapter concludes by taking the five design principles identified in chapter two and applying them to the analysis of the site to establish a guideline for the proposed design that follows in chapter four.

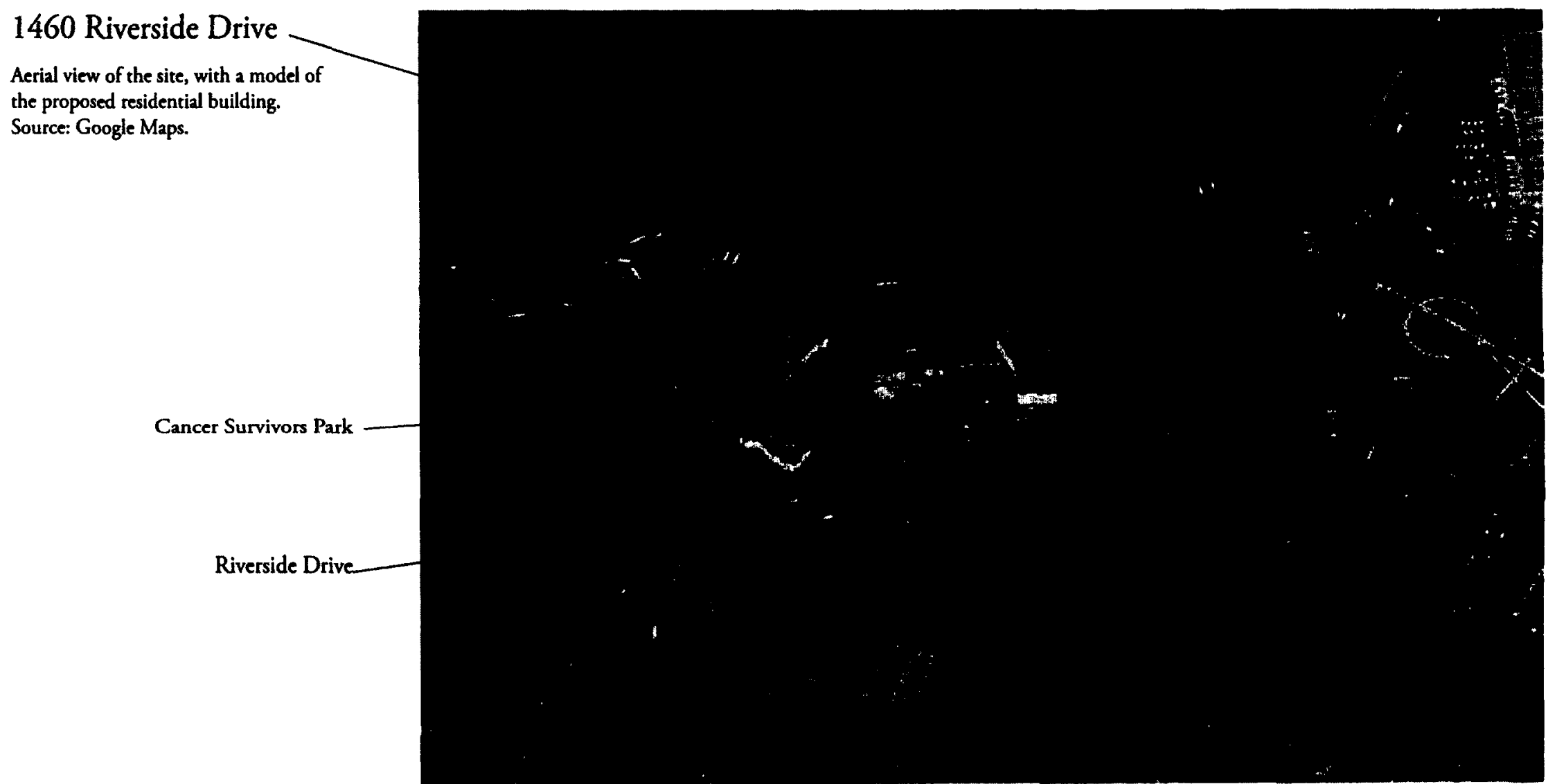




\section{Riverside Drive}

The proposed site is found at 1460 Riverside Drive, which is approximately 3.5 kilometres south and east of Ottawa's downtown core. The site is triangular in shape and is bounded by Riverside Drive on the south-east, Terminal Avenue on the north and the rail tracks on the west. West of the site, on the other side of the railway tracks, is a high rise condominium complex known as The Riviera. To the east, on the other side of Riverside Drive, is the neighbourhood of Alta Vista. This middle-class neighbourhood is made up of medium to large single family homes. Directly to the north is park land, the entrance to the Hurdman transitway station and proposed Light Rail Transit stop, and the continuation of Terminal Avenue, which provides entrance to the Via Railway Station.

Prior to 1828, the land in this area was densely forested. Around 1828, the land was deeded to

62 Harry and Olive Walker. Carleton Saga, (Ottawa, ON: Carleton county council, 1968) $\mathrm{p} 416$

63 Walker p197

64 E. H.Bennett. (1915a). Drawing 20B. Diagram of present built-up area and population density, showing also probable future expansion- future conditions. In Report of the Federal Plan Commission on a General Plan for the Cities of Ottawa and Hull Retrieved from chttp://www.planningcanadascapital.cas
Martha Burritt ${ }^{62}$, of the family known for Burritt's rapids, just south of Ottawa. Shortly after 1830 , the land was sold to the Hurdman brothers who used it to hew lumber. Its proximity to their lumber and train yards, presently where the Ottawa train station is located, made it a strategic plot for managing their lumber business. While their lumber business collapsed with the great fire of $1900,{ }^{63}$ it did not deter the brothers, who converted the parcel of land and an adjoining parcel into a profitable farming business.

Under the E.F. Bennett Plan of 1915, the land was designated for development. The Bennett Plan proposed the area to be a "built up" with a thin parkland that would follow the river. ${ }^{64}$ The specific site at 1460 Riverside Drive, however, was proposed for medium density residential development.

In the early 1940's the land, which then became part of Ottawa due to the annexation of the western section of Gloucester, became designated a city landfill. Although the site in question was not covered in waste, it was used as an access point to enter the landfill site. Since 1966, the site has been a green space and zoned for medium density residential and recreation use. 
E. H. Bennett, Drawing 20B

Showing the plan for Ottawa and the "built up" designation for the site.

E. H. Bennett. (1915a). Drawing 20B Diagram of present built-up area and population density, showing also probable future expansion-future conditions. In Report of the Federal Plan Commission on a General Plan for the Cities of Oztawa and Hull. Retrieved from:

<http://www.planningcanadascapital.cas

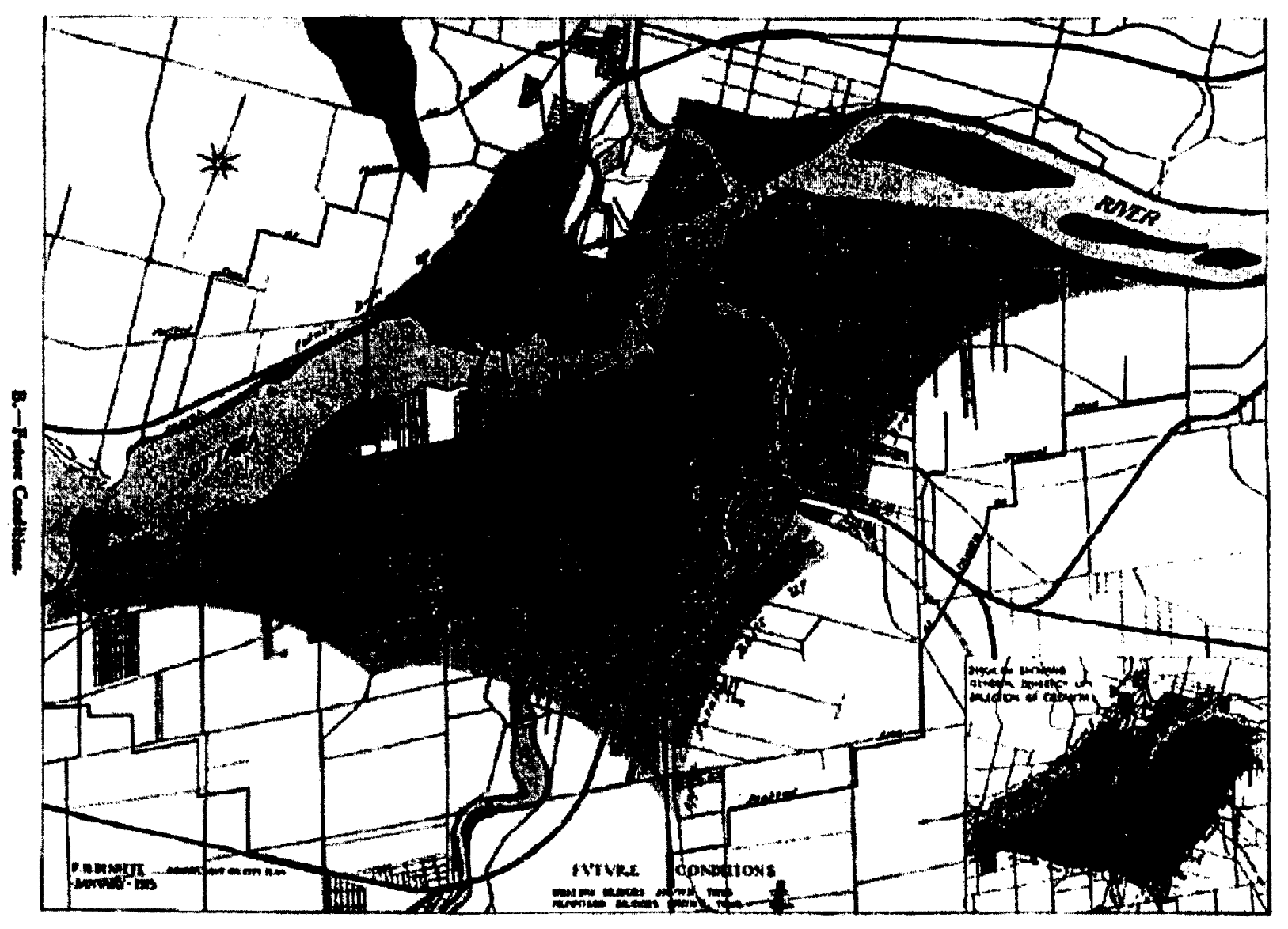

1460 Riverside Drive is on the south-west corner of the intersection of Riverside, Industrial, and Terminal avenues. The north-west corner of this intersection features a complex blending of an entrance to Hurdman Station, and access to Terminal Avenue - a side entrance to the train station. Kitty corner of the Riverside site is Ottawa's main Canada Post sorting facility, which is a large 5 story building. The south-east corner of the intersection features the Cancer Survivors Park, a public park that commemorates cancer survivors and offers space for contemplation and inspiration.

As its name suggests, Riverside Drive is a parkway that parallels a portion of the east bank of the Rideau River as it passes through Ottawa. Riverside begins at the intersection of the Queensway 
(Highway 417) where The Vanier Parkway ends and continues south to the intersection of Limebank Road and River Road, where it terminates. Several major institutions are located along Riverside Drive - The Riverside campus of the Ottawa Hospital, Canada Post's main Offices and their main sorting facility for Ottawa, Vincent Massey and Riverside Parks, as well as several federal government office campuses. In addition to these institutions, Riverside Drive also passes through several residential neighbourhoods, and provides a link from these neighbourhoods to downtown Ottawa. As a parkway, it is intended to carry swift traffic, and therefore features few but significant intersections with other arterial roads.

The Bennett Plan has assured that Riverside Drive has largely maintained its parkland character. However, where it passes in front of the project site, the character of the road becomes quite complex, as it widens and connects with Industrial Avenue and Tremblay Road. Just north of this intersection - where the Drive begins - are a series of underpasses and overpasses, which are part of the Queensway. The Canada Post sorting facility announces the beginning of Riverside Drive with an industrial character. As will be seen in the proposed site, the proposed landscape design for the site will work with the Cancer Survivors Park to mute the industrial character of this corner and create a "garden gateway" for the beginning of this river parkway.

Presently, 1460 Riverside Drive is a triangular patch of grass, which is bordered by a vegetation on all sides. The hill that has contains the rail tracks is planted low vegetation, while the small berm that separates the site from Riverside Drive is planted with trees. The land is tended by the City of Ottawa. The landscape is mostly flat; however there is a slight downward slope from the southwest corner of the site (where the rail tracks and Riverside meet) towards the north east corner of the site (at the intersection of Riverside Drive and Industrial Avenue). Presently there are no buildings on the site. Standing with your back to the tracks and looking south east the view would be of Riverside Drive, and the large tree covered berm that separates the road from the houses in the Alta Vista neighbourhood. This berm acts as a barrier between the Drive and the residential neighbourhood. Turning and looking directly east, there is a low-level view of the Cancer Survivors Park and the Postal sorting facility. 


\section{Site Selection}

\section{Street View}

The site as of October 2011.

Looking west

Photo: KE

65 Boucher p261

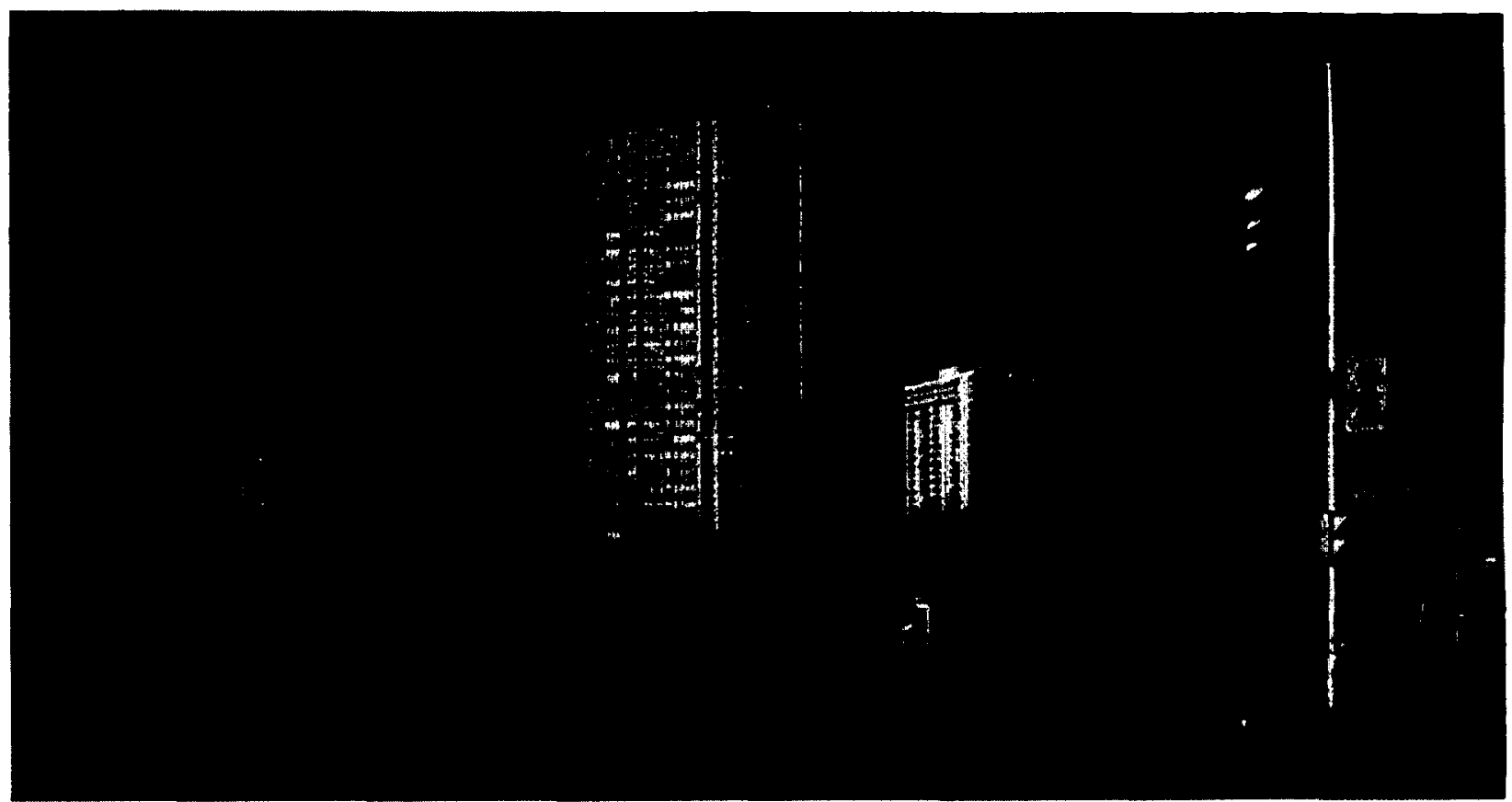

The site was chosen for its proximity to downtown and for its size, which offers the potential for a garden. It was also selected for the challenges of the site, specifically the nature and character of Riverside Drive and the proximity of train tracks. The location for this proposed thesis project depicts a reality that is presently faced in our urban milieu: large open areas are not readily available when wanting to develop and live close to the downtown core. The site may seem initially undesirable to potential dwellers, however it is the role of the architect, and their response to the site, that will invoke and sustain living well. The proximity to the core, the demand for density, and the attributes of this site represent both advantages and challenges that this project must seek to address.

It is rare that the architect has the luxury to choose a site to develop. Rather, it is more commonly the architect's role to be assigned a site, and to allow the site to provide input into the design. Palladio was assigned the site for the Rotonda. Almerico had purchased the land over a number of years, slowly acquiring parcels ${ }^{65}$ that ultimately lead to its size at the time the building was designed and built. 


\section{Site Analysis One}

Site location within central Ottawa

Indicates Public and human powered transit

Source: Google Maps

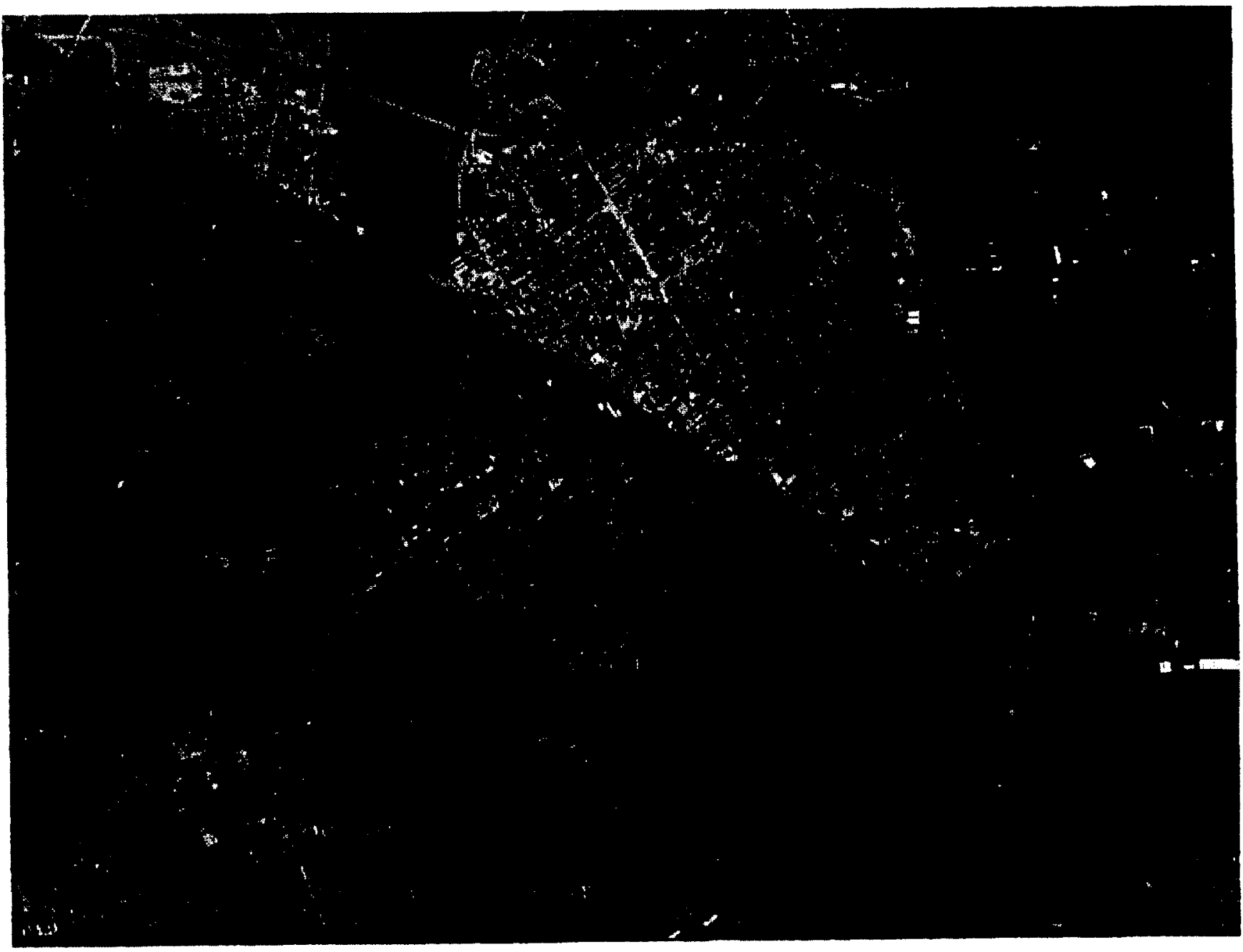


Site Analysis Two

Indicates human powered transit Source: Google Maps

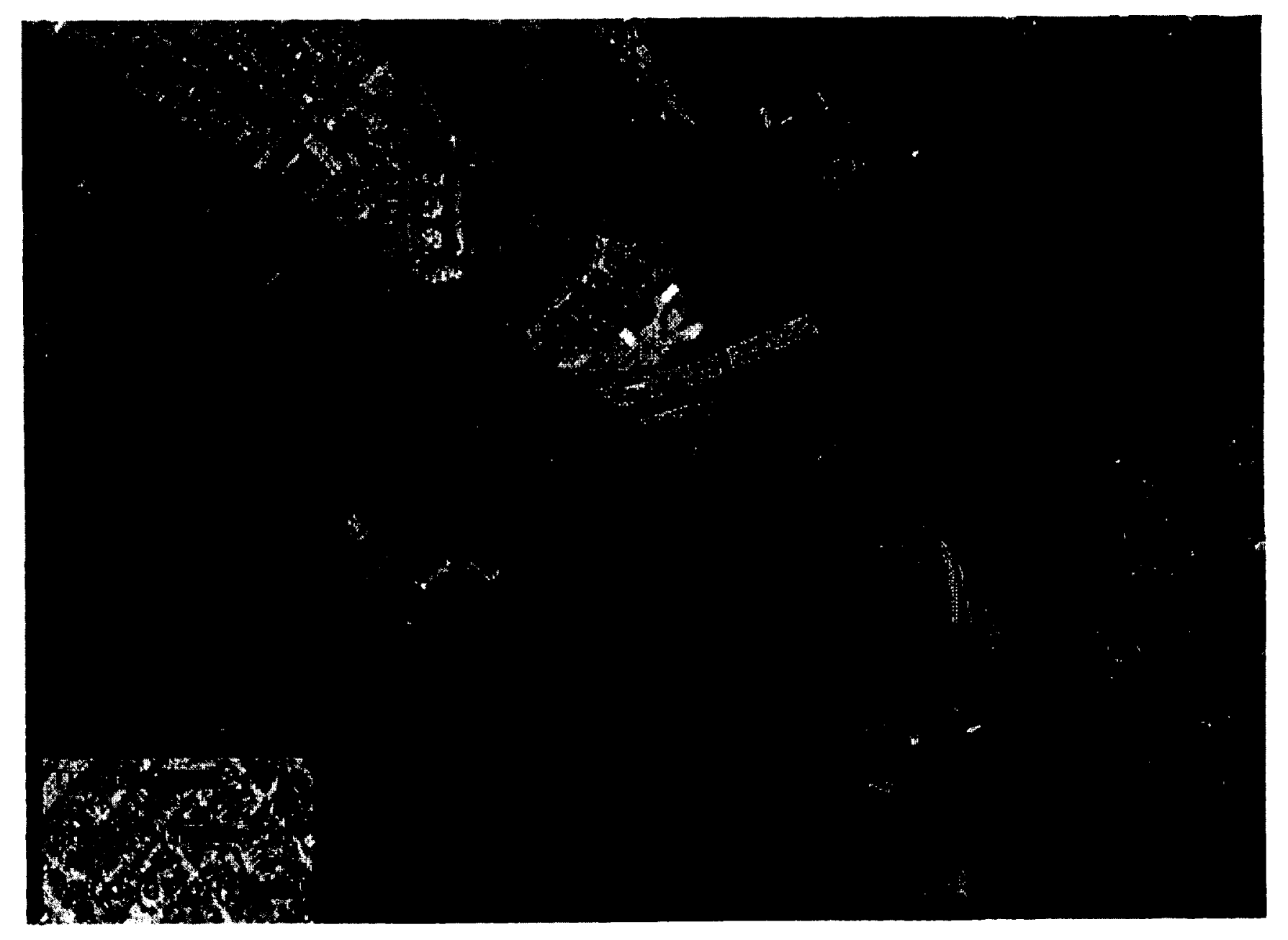


66 Sarah Bingham ec.al. Hurdman Station: Area Redevelopment Srudy (Kingston, ON: School of Urban and Regional Planning, Queens University, 2011)
There are few potential sites in Ottawa that would meet the characteristics defined in the previous chapter, and that are close to the city centre. A major consideration is the size that is needed for the garden. Other areas with a similar proximity to the city centre were sought and, with the exception of Riverside Park, only one other area might afford the space required, and would also be within the same distance of downtown. That area is Le Breton Flats. This area, interestingly enough, is very similar to the chosen site: a transitway slices through it, and will soon be converted to the LRT; the site is adjacent to but not directly on a river's edge and a parkway passes adjacent to the site. At Le Breton Flats, the available land area would back onto the transit route, while the front of the land faces Albert Street - a major commuter route that is just as busy as Riverside Drive. The development of Le Breton Flats has been ongoing for over 30 years and the National Capital Commission has identified this area for high density residential and mixed use development.

Although the plan for the "Flats" includes public park space, it does not allow enough space for a private garden within a residential project.

One other area under consideration was Riverside Park, a parcel of land adjacent to the selected site. It is located north and west of Riverside Drive and south of the Hurdman station. In 2011, a Queen's University study ${ }^{66}$ looked at this area for potential residential development. It identified a series of opportunities for the area and also three major drawbacks. The opportunities included the amount of land available for development, the proximity to Hurdman bus and LRT stations and walking distance to the downtown core. The drawbacks included that the area is designated as parkland, the area is on the floodplain of the Rideau River and finally the area was used as three separate municipal dumps from 1948 until 1966 and would need major soil remediation before development could proceed.

The chosen site for this project is adjacent to the third municipal dump that operated from 1964 to 1966, which collected the least amount of waste of the three dumps. The north end of the chosen site was used as an access point to this dump, however the site itself was not used for any form of land fill and it is not contaminated. Also, this site is protected from the floodplain. 
As recreation is seen as a contributor to living well, the site has many features that will enhance that opportunity. Its location lends itself to living without a car. It is a few minutes' walk to the Hurdman Station. It is surrounded by bicycle paths, which lead downtown and to other amenities. Equally important is the location of parkland within walking distance; the lengthy trails that follow the Rideau River are less than a kilometre away. Not only will these activities contribute to the dwellers' mental sustenance, but the use of human powered vehicles and public transit also promote sustainable living.

\section{The Site and Living Well}

The design approach defined in Chapter 2 is informed by the phenomenology of wine, which forms the basis of living well. It is also inspired by Cornaro's notion of sustaining happiness through built form, which we saw dutifully executed in Palladio's Rotonda. These examples combine to suggest that living well can be achieved by designing within architecture that is well thought out. The building would be grounded in history, while not being historic, to allow for its dwellers to be comfortable in something new. The building would be "infra-ordinary", that being a moderate size and one that is neither plain nor palatial. The building delights in a hierarchy of spaces, which unfold as one moves through them, while it provides access to clean air and a garden. The design ideas would also stem from the materials used in the design, in this case those identified from the phenomenology of wine.

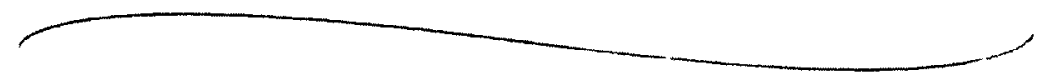

Applying the approach derived in Chapter 2 to the above analysis of the site we may consider the following guidelines for redeveloping and intensifying the Riverside site.

\section{Design within architecture, not of architecture}

The site poses challenges due to its location next to a busy thoroughfare and rail tracks. However through thoughtful consideration these challenges are easily overcome. The design is to be composed with the dweller in mind; distractions of developers' or personal aggrandizement would be avoided. Applying a positive sprit to the design will allow it to enhance the positive attributes of the site, while overcoming the issues of Riverside Drive, for example. 


\section{Grounded in history}

The proposed design is to be new and contemporary; it may however draw from history, specifically from the Rotonda. The site has a mixed history - a forest, then a farm, then an entry to a landfill site, and now an open space which does not contain any amenities for recreation. It would be easy to drop any sort of design on this site, due to its mixed history, however by grounding the design in historical precedent, it allows for a building that while being new encourages the dweller to feel comfortable in the design.

\section{In moderation}

Neither ordinary nor extra-ordinary, the design should be "infraordinary" or modest. In its 2004 Downtown Ottawa Urban Design Strategy 2020, the City of Ottawa proposed an increase of density of residential buildings in the downtown core. The site falls just outside of the strategies' boundaries, and is zoned for low density/recreational development. This thesis assumes that the intensification strategy will evolve to include areas adjacent to the core, of which the Riverside site is a part. The size of the site and the potential precedent established by The Riviera condominium makes it easy to argue for an additional series of towers on the site. These however are not modest buildings. Another series of residential towers would more than exceed any thought of density, however would not represent the conditions outlined in the design approach detailed in Chapter Two. Furthermore, such density would they meet the existing zoning of the site.

A more modest building should be proposed, one that establishes a middle ground of density, which meets the goals of the Urban Design Strategy. The density would be far greater than the housing found in the Alta Vista neighbourhood, across from the site, but less than what is found further west on Riverside Drive. This approach lends itself to the ideas defined for designing for living well. Being "infraordinary" also allows for space to be available for the garden.

Modestly designed units will also bridge the gap between many of the small "loft style" condominiums that are presently being constructed in Ottawa and the large houses found across the street and in many suburban developments. 


\section{In mystery}

The space of the site provides for a design of the garden that in itself will reveal its make up as people pass through it. The present open space will retain the same design principles identified for the building so as to create a garden that is not expressed in one "shot" as the open space that the site presently does. The use of trees, shrubs and paths will allow for vistas, and flower gardens that are not immediately seen, and glimpses of paths whose destination is not readily known.

\section{The need of a garden}

The chosen site provides the space required to meet the objectives of a building that will allow for a moderately dense residential building while meeting the guideline of the garden. The present site being an open one with only some grass will be significantly enhanced with the addition of the designed garden. The garden will be primarily for use by the residents of the condominium, much like the front yard of a suburban house. However, its presence on Riverside Drive will offer an added pleasant experience for passersby, enhancing the experience of visitors to the Cancer Survivors Park and assist in muting the industrial character of the Riverside Drive- Industrial Avenue intersection.

\section{Materials as tools}

Materials are chosen by the architect to inform and enhance the ideas projected through the design. Just as Palladio used material from the Rotunda's site, the history of the proposed site for this project allows for materials from the site to be used as well. In this case wood, which the site's history identified was an abundance in it past. The use of this material will predominate and be exposed, thus expressing through the building the history of the site.

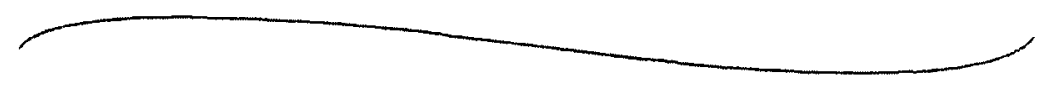

These design considerations as they are applied to the site will be carried through and further developed in the next chapter. Chapter 4 describes how, through the design guidelines established in chapter 2 and the analysis of the site, the proposed residential building will be designed with the expressed outcome that its architecture not only invokes but sustains happiness, and therefore allows its dwellers to live well. 


\section{Chapter Four}

\section{Project Proposal}

Riverside Garden

Scale massing model of proposed

Riverside Garden project.

Scale: 1:250

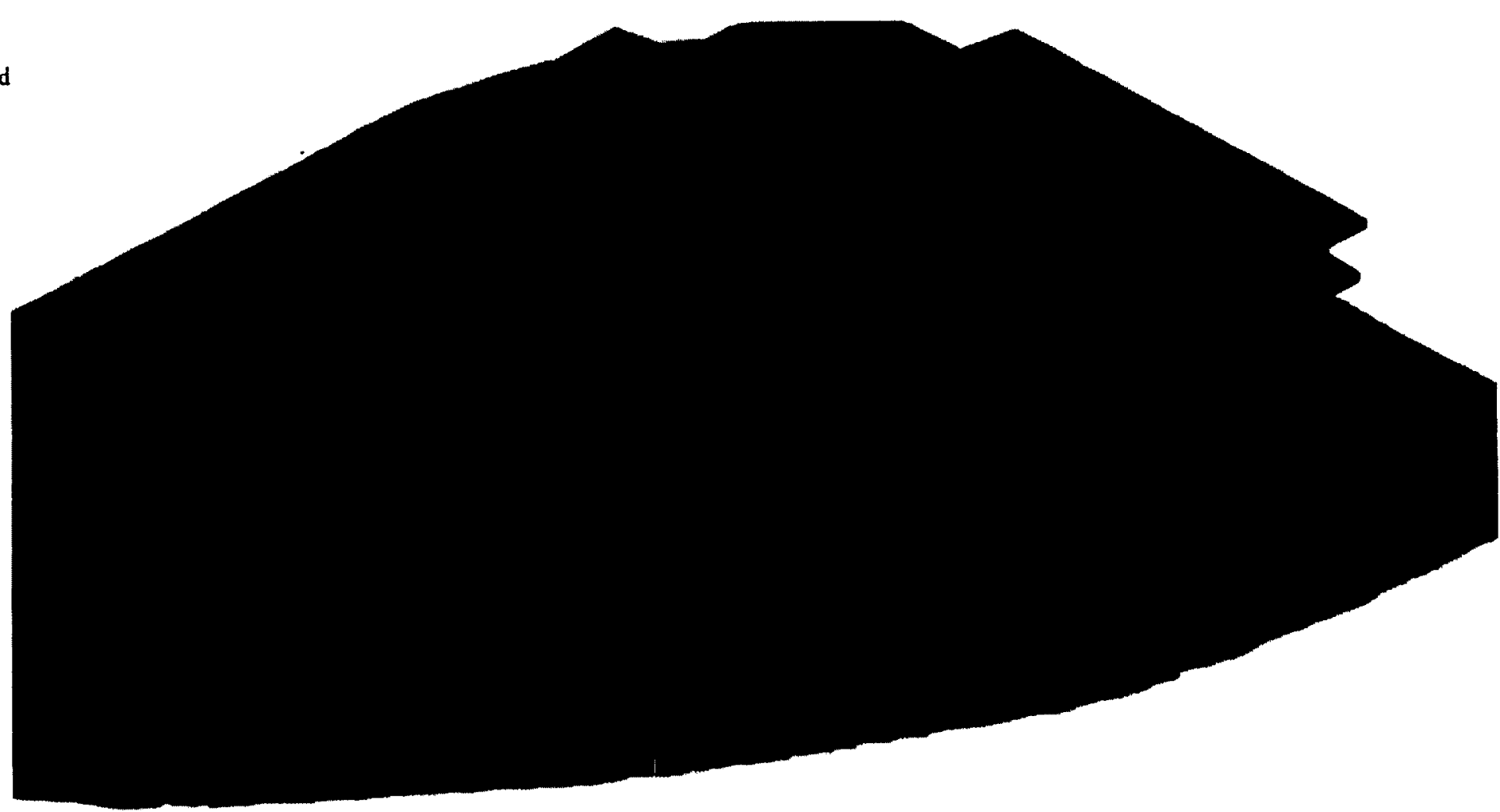


This thesis proposes the development of the Riverside site as both an intensification project and a proposition of living well through well-thought, well-built architecture conceived within the limitations of increased density. The proposed design has two significant elements: a medium density residential building comprising of 57 condominiums, and a large garden area fronting the building. Together these two elements, whose design is driven by the guidelines outlined in the previous chapters, work hand-in-hand to create a living environment that induces and sustains the elements that are needed to live well.

The layout follows the guidelines through the development of the phenomenology of wine and the ideas of Cornaro. The Garden consists of turf covered areas, flower beds for both annuals and perennials and a mixture of small and large coniferous and deciduous trees. In addition to the large garden fronting the building, small garden plots front each unit, allowing the dwellers to both participate in the community decisions of the Garden and hands-on gardening of their own garden area.

The proposed interior garden is in the large atrium that connects the two wings of the building. This garden is a year-round green space affording the dwellers and their guests the same experience that the outdoor garden provides but on a smaller scale.

\section{The Dwelling}

The proposed building is a multi-unit condominium, designed to provide residents with a sense of pride and comfort. The design is well-thought and executed with pleasure and the expectation that the building will be well-built so to ensure that it invokes and sustains the happiness of the dwellers. The design of the building aims to create a sense of anticipation and mystery, as well as visual and tactical experiences though its materiality. The building features defined spaces that may be used for sharing time with friends, family and neighbours, but also areas for retreat and recharge. The building is of history, but it is not historic. It is a contemporary structure that borrows from the essence of the Rotonda, but it is a new design where the dwellers will feel comfortable living their contemporary lives. 
The building itself is a 57 unit structure, of which 9 units are single bedrooms, 42 units are two bedrooms of various sizes, and 6 units are three plus one (small) bedroom. The height of the building is 6 stories and is divided into three 2-storey horizontal sections. Each section contains an internal main and upper floor, within each unit. Only nine single-bedroom units are located on a single floor.

The three 2-storey sections are stepped back one from each other, such that the second section is offset by six meters from the first, and the top section is offset 6 meters from the second. This stepping, or terracing, of the building provides for a large outdoor hall and garden area, which fronts each horizontal section of the building.

The building is made up of two wings. The west wing features two sections that run north - south along the west side of the site, while the north wing runs east-west along the north side of the site. A large enclosed atrium connects the two wings at all three levels, and houses the indoor garden. It also acts as the central entrance to the edifice.

The two sections of the west wing are separated by a large outdoor stairway that provides access to the upper terraces. In effect, the two wings enclose two of the three sides of the triangular site, creating a third border for a large landscaped garden for the use of the residents.

The overall size of the building in relation to the site contains far more units then the area of the same size across the street, which contains only 17 single family homes on a comparable area of land. Put another way, on this site only 17 family homes would fit instead of the 57 units proposed. In the 2004 Downtown Ottawa Urban Design Strategy 2020, the City of Ottawa proposed an increase of density of residential buildings in the downtown core. Although the selected site falls just outside of the strategies' boundaries, the increased density on the site responds to today's environmental concerns. The proposed density is a medium ground between the high density Riviera condominiums west of the site, and yet it is still much denser than the Alta Vista neighborhood to the east. As such, it provides a comfortable transition in density. 


\section{Axonometric}

Looking north-west, the Garden and terraces are emphasized

Scale: 1:150

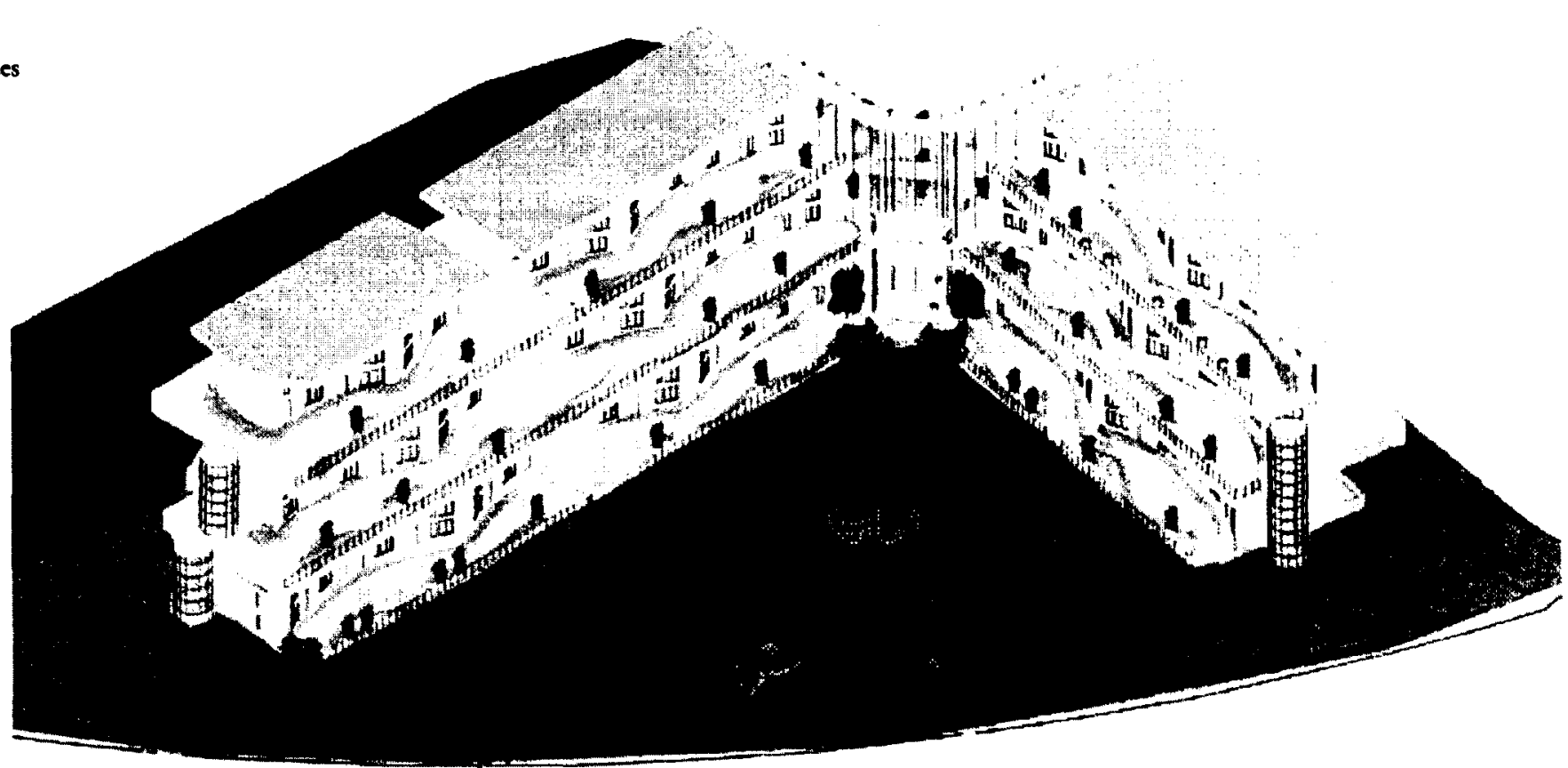

\section{Discussion}

The design of this project acknowledges that it is part of a broader strategy of urban intensification, and therefore seeks to play a role in developing a vacant urban site in a way that contributes to city growth, while also generating desirability for urban living.

The increased density on the site responds to some of today's environmental concerns, specifically the growth of the suburban areas which are forcing people to commute longer distance. This project seeks to mitigate the growth of autos on the road and the increased negative environmental impact that has by situating a residential development adjacent to public and alternative forms of transit. By increasing the population density living on the proposed site there is a reduction of long distance commuters as well. In this case, its proximity to the downtown core increases the likelihood of using public transit or human power to commute, further reducing the negative effects associated with suburban living. 
The scale of Riverside Garden offers a transition from the intense development of The Riviera condominiums and the much less dense, single family dwellings of the adjacent Alta Vista neighbourhood. In this way, the Riverside Garden provides a link between the two neighbourhoods, while also suggesting how to begin to urbanize infill areas that are peripheral to the city core.

Thinking about the civic role of urban infill development, the Riverside Garden is designed to foster a sense of community and social integration both within the project site, and between the project and its broader environment. Within the project site, a large number of dwellers are concentrated in a relatively small urban space, all the while affording privacy within each dwelling unit and strong links with a communal gathering space outside the dwellings, where the opportunity for interaction can be found. Outside the project site, the entrance of Riverside Drive will start with a large garden area which, when mature, will compliment the heavily treed berm on the south side of Riverside. This acts as a natural filter, which enhances both motorists and pedestrians experience as they are making their way along Riverside Drive. The development of the garden on this site will also enhance the experience of visitors to the Cancer Survivors Park. Instead of looking across the present grassy void towards the many city buses entering the Hurdman Transitway station, their view will be of an expanse of greenery which will block the view of many of the busses.

The garden landscape

\section{The Gardens}

Situating the proposed building at the perimeter of the site allows the building to create a separation from the garden to the train tracks to the west and the bus lane and roads to the north. This placement also permits a larger area for the creation of the garden and enables views towards the garden from every unit. A heavily planted berm separates the garden from Riverside Drive and helps to reduce the sound of traffic during the morning and afternoon rush hours, contributing to enjoyment of the site. 
A main feature of the defined guidelines for living well is the garden. The phenomenology of wine describes how a sense of happiness is derived from the garden and Cornaro expresses how it plays an important role in sustaining that positive state of mind. The garden is a focal point of the architecture. It is the landscape that is considered an essential pleasure which was understood and executed by Palladio. ${ }^{67}$ The Rotonda offers four different views of the garden from the sala. The landscaping of the Riverside Garden is also designed to bring pleasure to the owners, as all the units look out onto it. The Garden is intended to be maintained by help under agreement by the owners, so the owners receive the enjoyment of the Garden without the need to spend all their free time maintaining it.

From the building the Garden is accessible from the first floor terrace. There are 5 entry points, one at each end of the building, one at the midpoint of each wing and one from the central entrance. From the midpoint of each wing a ramp or slope connects the terrace to the garden. From the central entrance there are steps that lead down to the Garden.

A central axis path leads from the steps to a large circular gathering point, located close the centre of the garden. Secondary paths branching from the other entry points also meet here. Another path runs along the perimeter of the garden. The portion of the path that runs along the first floor terrace is open to the garden; however, along Riverside Drive it is separated from the road by the large berm with large trees, while on the other side of the path a lower berm also with trees creates a sense of enclosure as people stroll or jog along.

As there is a curve of the property along Riverside Drive, the path also curves, creating a sense of mystery as the other end is not visible. To add to this experience of mystery, at the midpoint of the path a thicket of trees is planted and the path appears to come to an end, however smaller paths allow those out for a stroll or a jog to continue along making their way through this thicket. Once past, they will continue along to where the path reconnects with the portion along the terrace wall. From the central gathering place, a path leads to the thicket where people may connect with the perimeter path. 
To the north of the central axis path are flower beds and manicured gardens made up of perennials, annuals and small bushes that the dwellers may walk amongst, sit on the landscaping furniture and enjoy company or solitude among the visual and fragranced pleasures of the garden. The part of the garden that is south of the central axis is open greenery, providing a place for children and adults to recreate and play. This area can be used for pickup games of soccer or tossing a ball or Frisbee. In the winter it may be flooded and provide an outdoor skating rink.

The main exterior entrance to the garden is from Riverside Drive and is found where the central path dissolves into the thicket. The entrance is not predominant, however it is intended for use of the dwellers and their guests. By shrouding this entrance in the thicket of trees and bushes it heightens a sense of anticipation for those who enter the property that way, especially for those who are arriving for the first time. Those who know where it is will enjoy the passage through the thicket and through the Garden to their units, while those who are new to the site will enjoy discovering the passage through the thicket and on to the building. This entrance is not a gate but is open, suggesting that the Garden is intended for the residents of the building, much like the front lawn of a house is intended for the residents of that house.

Entrance to the Garden and the building is also available from the corner of Riverside Drive and Terminal Road. The planted berm here begins to slope down to ground level along Terminal Road. As with the entrance from Riverside Drive, this path is shrouded from view by trees and bushes. This entrance path leads to the perimeter path, as well directly to the first floor terrace and the stairway that leads to the second and third terraces.

The berm that runs along Riverside Drive is high enough to assist in shielding the Garden and building from the street noise during rush hours. The berm is to be planted with a variety of tress. This includes a mixture of small and large coniferous and deciduous trees. The selection of trees provides greenery year-round, and during the summer provides shade. The additional foliage of the 
deciduous trees provides an additional sound barrier, allowing the residents to enjoy the summer with their windows open.

The trees on the site are found predominantly on the berm, which is at the perimeter of the site. This location also enhances the site at the street level for the motorists and pedestrians using Riverside Drive. The berm, while planted with trees, will also be landscaped and planted with bushes and flowers providing additional pleasurable experience for those on the street side of the property. As the berm extends north it will turn west to follow Terminal Road. Here it will slope down toward street level as it passes behind the north wing of the building, shielding that wing of the building from the entrance to the bus station. The berm and trees will also contribute to bringing life to this barren and industrial looking intersection, while complimenting the Cancer Survivors Park across the street. The combination to the landscaping of Riverside Garden and the Cancer Survivors Park will create a gateway that is fitting for this important arterial road.

\section{The Central Entrance}

The Atrium is the six story winter garden that connects the north and west wing of the building. It comprises glass walls on the north and south elevations and partial glass walls on the east and west side. The main roof is at the same level as the rest of the building, however there is a 1.5 meter clerestory rising above that. For cyclists and motorists, access to the building will be via Terminal Road. A semisubmerged single level parkade offers parking for the tenants and guests bicycles and autos.

The roof of the parkade, which constitutes the base of the first terrace, is a meter above ground level. The entrance to this parkade is under the Atrium. The Atrium is accessible from the parkade via an elevator, which rises to all three terrace levels, and stairs which rise to the first terrace level. The Atrium is the "joint" that connects the two wings and is also the main entrance to the building.

The main entrance faces the Garden. It consists of five columns, their shape borrowed from a horizontal wine bottle, that rise up three stories. Between these columns are the main doors that open into a large vestibule. The approach from the Garden to the entrance is along the main Garden 
path, which is lined with small trees and shrubs. This greenery continues up to the terrace and transitions uninterrupted into the vestibule. (Figure 1). The all-glass curtain walls and doors blur the definition between outside and inside. Entering the two story vestibule, the path and vegetation continue through the next set of doors and into the winter garden. The shape of the columns and glass curtain wall are new, the inspiration is of history.

At the first terrace level, the Atrium has the most floor space, (figure 3). Opposite the main entrance is the rear entrance, which allows access for pedestrians who are entering the building from Terminal Road. This entrance would be used primarily by dwellers heading to or coming from the Hurdman Transit Station. Also at the rear of the Atrium are stairs that wind their way up to the second terrace and from there to the third (figure 2). In the north east corner of the Atrium is the elevator.

Beyond the means of circulation, the main floor of the Atrium is dedicated to the indoor Garden, which is over $\mathbf{4 0 0}$ square metres in size. It is landscaped with trees and shrubs of various sizes, with flower beds that border a series of paths which lead to the various access points and more importantly to secluded areas where one may recompose during the cold winter months. There is a central gathering point that mirrors the one in the Garden. Surrounded by vegetation and garden furniture, this area provides a place for the residents to gather as a community.

At the second terrace level in the Atrium there is additional landscaping, but on a smaller scale than on the first level, (figure 4). At this level people may connect from one wing to the other by passing through the single story level vestibule. In this vestibule, which is above the main entrance vestibule, they may proceed through additional doors into the Atrium. From this level there are views of the Garden and the park land north of the site. There are also two large openings in the floor that allow residents to view the activities on the first floor. These openings also provide additional light to filter down to the first level. At the back of this level in the Atrium are the winding stairs that lead down to the first level or up to the third level. 
The third level in the Atrium also provides landscaping, but again on a smaller scale than the levels below, (figure 5). At this level there is an indoor connection to the two wings of the building, as well as the staircase and elevator access to the levels below. The landscaping is small but intimate. The views from this level are panoramic - nearly 360 degrees. Just like the level below, there is a large opening in the centre of the floor allowing the dwellers and their guests to see all the way to the first level, while allowing for additional lighting to filter down to the two levels below.

\section{Terraces}

The terraces are intended to be used as small gardens tended by the dwellers. (Refer to figures $12 \& 13)$.The terrace off the first floor is one meter above the garden level. Two more terraces extend approximately 6 meters above each other, the height of each section of the building. The terraces aim not only to bring the garden closer to each residential unit, but they also act as the main procession that residents will follow in order to enter their individual dwelling units.

Since gardening is the largest pastime of Canadians, the need for available gardening space is met with these terraces. Just as with Palladio's clients who considered themselves farmers (farming then

68 Hoberton $p 154$

69 Hoberton p 154 was seen as gardening is seen today, a pleasurable pastime $)^{68}$ with the mere act of placing a "clipping or young plant"69 in a pre-dug hole, the access to small terrace gardens will bring the owner immense pride. The terraces have areas that each dweller may design and plant as they see fit. The process of doing so and the close proximity of the terraced plots to the individual condos will assist in bringing the neighbours together, and contributing to the social aspect of the phenomenology of wine.

Access to the terraces is provided from either end of each building wing. Locating the entrance at the end of the wing causes residents to walk along the length of the terrace before entering their own unit, and therefore encourages interaction with the garden by providing an "unwinding" as residents transition from a work day to home. The terraces also encourage interaction with neighbours.

The massing of the front elevation of the building is curvilinear, where the bow extends into the building, creating a large area in which people can gather and garden. While the terraces themselves 
do not follow the elevation of the building, the next terrace up creates an overhang and shelter for the residents below, like an outdoor vestibule. The curvilinear shape of the front elevation of the building is inspired by the sala of the Rotonda and its entrances as they were used for public functions.

Palladio writes that "halls are designed for parties, banquets, as the sets for acting out comedies, weddings and similar entertainment, and so these spaces must be much larger than others and must have a shape that will be as capacious as possible so that many people can gather in them comfortably and observe what is going on." ${ }^{.70}$ Following from this, there is ample space on the terrace where the elevation of the building curves inward so as to allow for gathering of friends and neighbours, as well room for garden furniture and barbeques amongst the plant beds and walking path. The path slowly undulates close to the building and then slightly away from it, creating a blur in the boundary of public and private space. While a portion of the terraces are used for family activities, they are also shared by other residents who may stop to chat, or pass by and simply wave hello.

\section{Interior: hierarchy and delight}

(Refer to figures 6 through 11)

The anticipation of first-time visitor walking along the terrace, which is integrated with the beauty of the gardening and the views of the Garden, will increase as they make their way to the dwelling unit.

The terraced vestibule, like the front porch on many homes in Ottawa, is outdoors and represents the threshold where a homeowner meets her guests. Once past this main entrance, a guest enters a space that they have been invited into, the dwelling. After the anticipation of the terrace, imagine the disappointment if upon entry the entire apartment is presented, as is often the case with today's trendy "loft style" condominiums. Similar to opening a bottle of wine only to discover its aroma and taste are exactly the same and do not change as the wine breathes. In these dwellings, the sense of anticipation and the delight of uncovering a mystery are maintained with a floor plan that refuses to reveal all of its secrets. Here there is a hierarchy of rooms, public to private.

The dwellings themselves are, as Cornaro suggests, well thought out. The length of the unit represents the depth of the building, with windows and doors on each end. Each dwelling is 
71 F. Alton Everst. The Master Handbook of Acoustics. Blue Ridge Summit, PA. Tab Books Inc, 1989 p161

72 Frascari p 5 separated by a double clay brick wall, with a chase between each brick wall. This space is used to house columns that support trusses and any mechanical systems that require a vertical chase. This space also creates a sound barrier, ${ }^{71}$ which is important to achieving the quiet needed to be able to contemplate in peace, or with the stereo playing, without being offended or offending your neighbours.

Upon entering the unit, the visitor is met with a chorus of materials: clay brick on the side walls of each unit, which the owner may choose to leave either unfinished or finished; white oak floors in the public space, clay tile on the kitchen floor. Each material is influenced by the phenomenology of wine, chosen from the region, and for their ability to enforce the ideas of the design itself. They invoke a warm response, and one of pleasure in their quality and feeling of warmth, which is both visual and tactile. Both the dweller and their guests know that these materials are natural, that they age well, and that they require little effort to maintain. These materials, as Cornaro argues, will only be acceptable for durable and sustainable constructions. ${ }^{72}$ The selection of materials help provide that sustenance of mind extending the pleasure one would experience when sharing a fine wine with their family or guests.

Inside the dwelling entrance, there is a vestibule and closet space for coats if there are any. In most cases, the "public" bathroom is also located here, so that the visitor does not have to invade the privacy of the hosts to find relief. The visitor would then turn and step down into the living room, which opens up and appears larger than its sunken floor and large windows would suggest. In most units, this semi-public space also includes a dining area. In the larger units, the dining room is separated by a partial wall or two steps up to the main floor level.

As one moves through the unit a mystery unfolds. If we are talking about a guest, they will know that their relationship with their host is strong as they are invited into areas where perhaps other guests, who clearly would be more casual acquaintances, would not be invited to go. Passing through the living and dining area, one enters the kitchen. With this transition, one begins to move from public to private, as the kitchen is not completely opened to the rest of the unit. The kitchen 
threshold is comfortably sized, but like the glass appropriate to its wine, the opening is designed to contain kitchen aromas, releasing only small hints to the nose that stands close to its door. To really appreciate the olfactory pleasures that the kitchen can produce, only a hint is allowed to travel through the unit while meals are being prepared. The complete appreciation is found while in the kitchen or at the opening.

Beyond the kitchen are a set of stairs that will take the resident or guest up to the second floor, where private bedrooms and bath are found. In the single storey units, these private spaces are found on the same floor, just beyond the kitchen.

Off of the kitchen is a small balcony accessible through large French doors. This balcony intends to provide the dwellers a quiet outdoor retreat, sheltered from their neighbours, where quiet socialization or contemplation may take place. The kitchens are ample in size and provide an area for the family to pursue homework, hobbies and other activities that they would choose not to do in the more public spaces or their bedrooms.

In all but the single bedroom units the bedrooms are upstairs. In the two bedroom units the second floor is accessible through the kitchen. In the larger units, the stairs may be found adjacent to the front entrance. In these dwellings, the second floor contains the master bedroom at the rear of the unit, and a second bedroom at the front.

The second floor plans are all central hall plans, with the hall providing access to the front of the units where, through French doors, views are afforded to the garden and terraces. The combination of these doors and the large movable windows in the bedrooms on both sides of the units allow for cross breezes in the summer, effectively reducing the need to use mechanical air cooling systems, and provides for cool air to assist in keeping ones thoughts sound and sustained. ${ }^{73}$

The dwellings are positioned such that even those with direct southern exposure will receive the morning light, which will help warm the front bedrooms in the winter months. 
74 Juhani Pallasma "An Architecture of the Seven Senses" Questions of Perception, Phenomenology of Architecture. (San Francisco: William Stout, 2006) p29
The master bedroom features an ensuite bathroom, which is accessible through a generous walk through closet. The closet serves two functions: it creates a separation between the bedroom and the bathroom, as well as from the bedroom and the hallway. In both cases, it helps to reduce sound transmission, thus ensuring privacy in the master suite. Each ensuite bathroom has a large bathtub, which allows for an escape from a busy day.

A feature of all dwellings is ample in-unit storage, a convenience sadly lacking in many of the "loft style" condos built today. In all cases the storage is accessible off the kitchen, and offers the dweller space for our consumer life style. Perhaps unusual, the storage space has a window which brings natural light into the room, and therefore provides the option to make it a guest room or den, if the storage requirements are not too stringent. However, the window is small so as to mitigate temperature fluctuations within the storage space. This would make it an excellent space for the dwellers' wine collection.

\section{Exterior: materiality and massing}

The chosen materials are influenced by history, but are not historic. The phenomenology of wine and the character of the site drive the design ideas to provide a visual and tactile experience. The elevations of the building are composed of glass, stucco covered clay brick and wood - materials typical to wine, but also typical to residential buildings in Ottawa. The glass sections are composed vertically and run from the base of each terrace to the underside of the terrace above. These glass sections house the doors and windows for each unit, and divide the stucco/clay brick, in effect making the stucco/clay brick appear as pilasters. The rough stucco covering the brick creates an experience that is both tactile and visual, as sunlight creates a rich play of shadows as it moves across the building elevation. The tactile experience will be heightened and sustained through time, as the texture of stucco's pitted surface changes as the material ages. ${ }^{74}$

The experience of winding a path along the terrace is heightened by the use of a combination of materials on the building facade. At the points where the curvilinear walls meet, the stucco surface 
is punctuated with vertical wood strips. The wood serves to soften this joint, both literally and metaphorically. The transition from the wood to brick/stucco is accommodated by a strip of copper - a technique borrowed from the making of wine barrels. The use of copper to separate the stucco from the wood sections creates a break from one material to another, while adding an ornamentation that increases the play of light across the stucco. It also causes the dweller to experience a mental break in the instant it takes them to become cognitive of the transition between these two materials. Copper, like good wine, ages well. As it ages, the patina developrs to create a slow and ever-evolving visual experience of the building's own evolution.

A joint also occurs between the stucco/clay pilasters and the glass sections that house the windows and doors. The windows and doors are also encased in wood. The spandrels above the doors and functional windows are in colored glass, much like the variety of glass one finds in wine bottles. As light passes through the coloured glass, it dances across the interior floors and walls. The ever changing light creates a simple but pleasant phenomenon for the dweller to observe in different ways, at different times and in different seasons. In the evenings, the play of light is reversed where indoor light spills out, and provides a visual play across the elevation of the building. The windows and glass-paneled doors make up the glazed section of the elevation bringing plenty of natural light into these spaces while affording year round views of the terrace and beyond to the garden.

\section{Tectonics}

Because the terraces cantilever over the units below (except for the terrace on the ground floor), a truss system has been designed to accommodate the cantilever. The depth of the trusses, and thus the terraces, are just over four feet $(1.4 \mathrm{~m})$. This depth allows for more than a few potted plants. Instead, the truss depth of 1.4 meters provides enough depth and strength to accommodate a perennial terrace garden, by allowing for small trees, as well as a wide range of perennial and annual plants, and hard landscaping. Where the units sit over the trusses, the depth provides space for a sunken floor in the public rooms of each unit, as well as ample chase area for mechanical systems. This is useful for future-proofing the building; that is to accommodate new technology changes and improvements without having to rip down walls. 
The trusses span the depth of the building and are placed between each unit. They are supported by columns, which run in the space between the brick walls that separate each unit. Within the depth of the truss space, spanning laterally, are smaller lighter trusses that support the main floor and second floor ceilings of each unit. As the units and terrace step back, each of the three sections of the building have trusses supporting the terraces and the roof.

The use of these trusses allows for each unit to be column free with the interior walls on the first floor assisting in the support of the second floor of each unit. Since the ceiling of the second floor of each unit is supported by the truss system, the walls of the second floor are easily movable, since they are not load-bearing. This will permit easy customization to suit the dweller's needs, both in the first instance and in the event of future dwellers.

The depth of the trusses on the third section, which holds up the roof is less than the trusses supporting the terraces. This variation in size creates a visual stop at the top of the building, while still providing a chase to the units below and support for a variation of a green roof proposed for the building. Borrowing directly from wine, there will be provisions for growing vines on the roof. The large leaves of the vines provide shade in the summer and thermal gain in the winter when the leaves have fallen off. Vines are happiest in well-drained rocky soil. They are surprisingly tolerant to drought but will also grow under wet conditions. The vines can be planted in commercially available green roof planters, while low maintenance green roof plants may be used to absorb additional rain runoff.

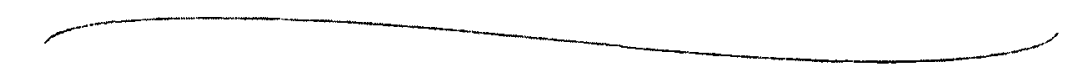

The proposed design seeks to provide the opportunity of living well within a dense urban environment. The building is new but familiar, and uses materiais that invoke pleasant experiences 
and offer the dweller well-thought and well-built public, semi-public and private spaces that induce the essence of the phenomenology of wine. Situating the building in a large garden and providing access to that, as well as personal garden plots, provides access to clean air, therefore allowing the Riverside Garden to contribute to the sustained well-being of its inhabitants. The landscaping, designed for the dwellers' sustained pleasant state of mind, also improves the experience of the inhabitants of the city at large by enhancing the entrance of Riverside Drive and subduing the industrial character of the intersection where the site is located. 


\section{Conclusion}

Many, but not all present day residential constructions seem to be quick and easy —quick to design with little thought or care and easily built due to the lack of design details. Urban high density development seems to favour an approach that gets the most possible dwellings out of the site, while neglecting .... This is usually achieved by taking the approach that Frascari decries: to design of architecture, rather than within architecture. That is to say, the goals of many developers and in some cases the architects are about fashionable designs of the day to maximize financial return without consideration of the assisting the dwellers achieving a positive happy state of mind. ${ }^{75}$ Though many of these buildings are quite habitable, the approach is skewed against the dweller. If these residential buildings were able to achieve a greater balance between the needs of the developers and architects and those of the dwellers then the final product may be better. The objective of this thesis is to show that a balanced approach - one that looks to incorporating the design guidelines that stem from the essence of the phenomenology of wine and the ideas of Cornaro into the building's design - may produce a result where all parties benefit more fully from the resulting built form.

By using the design guidelines developed in this thesis, we might overcome some of the inherent difficulties in designing urban residential buildings that need to meet density and low environmental impact goals. Often, as is the case of this design proposal, the site is not the most desirable. It alone presents a challenge that perhaps developers and designers who think of architecture may overlook as a possible site. However, we have seen that the guidelines stemming from the phenomenology of wine and Cornaro's thinking within architecture allows for the challenges of this site be overcome. Situated on a busy thoroughfare and rail tracks, the site actually lends itself to the goal of living well, and benefits from the guideline that suggests the building be situated in a garden. The landscaping and selection of trees in the Garden reduce the sights of the busy parkway as well reduce the noise from cars. The Garden also contributes to the broader community by transforming a somewhat barren piece of land into an interesting greenspace that, in concert with the Cancer Survivors Park across the street, acts as a gateway and announces the beginning of Riverside Drive 
The phenomenology of wine and Cornaro's ideas not only allow for the challenges of this urban site to be overcome, they provide the basis for a design of a building that differs and is preferable to many of present day condo developments. The building is designed within architecture, that is with the dweller in mind; it evokes a happy state of mind while sustaining that happiness so as to allow the dweller to live well.

A design that is of history creates a sense of familiarity, easing the mind of the dwellers, removing the anxiety that comes from something new and different. The moderate size of the building and the dwelling units promote a greater community environment, and the happiness that comes from that, while still meeting the goal of dense urban living.

The interior layout of each dwelling is carefully designed to evoke a sense of mystery by not immediately revealing itself, as is often seen in other contemporary multi-unit residential buildings. This gives pause to dwellers and guests alike, as they think of where they dwell while also providing the ease of mind by the separation of private room from public rooms.

Riverside Garden is situated on a site that allows for views of the Garden from all units, while the terraces allow for social interaction. The Garden is equal in importance to the building itself, and affords the dwellers the ability to live well by providing a place to recreate, to socialize and to find places of solitude in which to recharge after a day of modern living.

The selection of materials furthers the pleasurable experience of the building by providing a visual and tactile encounter. The choice of materials also aims for a lasting effect, as they are quality materials that are proven over history to be long-lasting with a minimum environmental impact.

By identifying a site, that on its own and in its predesigned state is not an idyllic setting for a dwelling that would promote a good life, a test is created. Can a less than perfect site be developed that will allow the dwellers to live well? Indeed, through the guidelines established from the essence 
of the phenomenology of wine and the ideas of Cornaro, a design is proposed for a well-thought and well-built building that succeeds in invoking happiness and the mental sustenance of that happiness, so the dwellers may live well. 
Figure 1

Scale: 1:150

The Central Entrance
Images

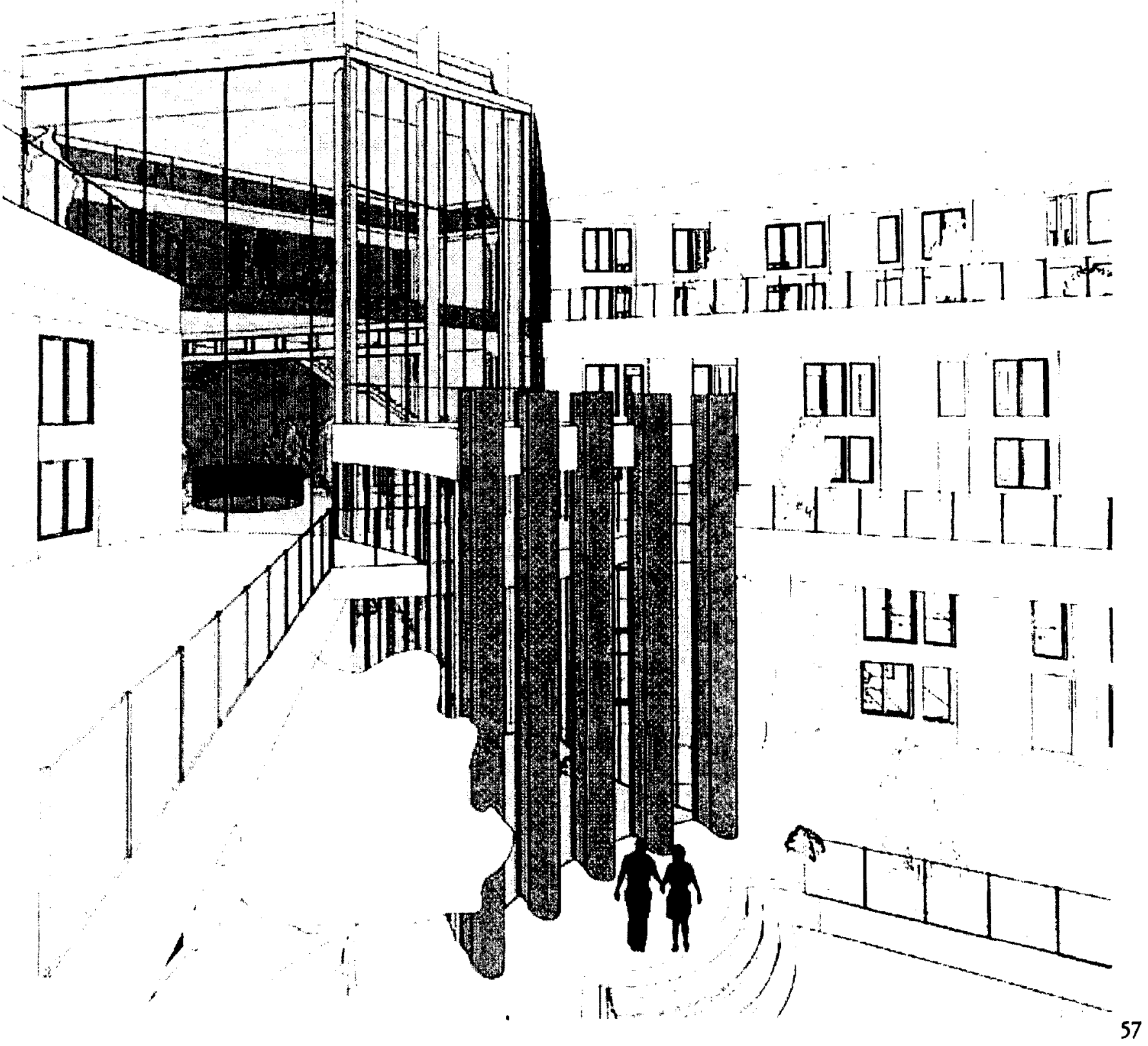


Figure 2

Scale: 1:150

The Atrium Rear Entrance
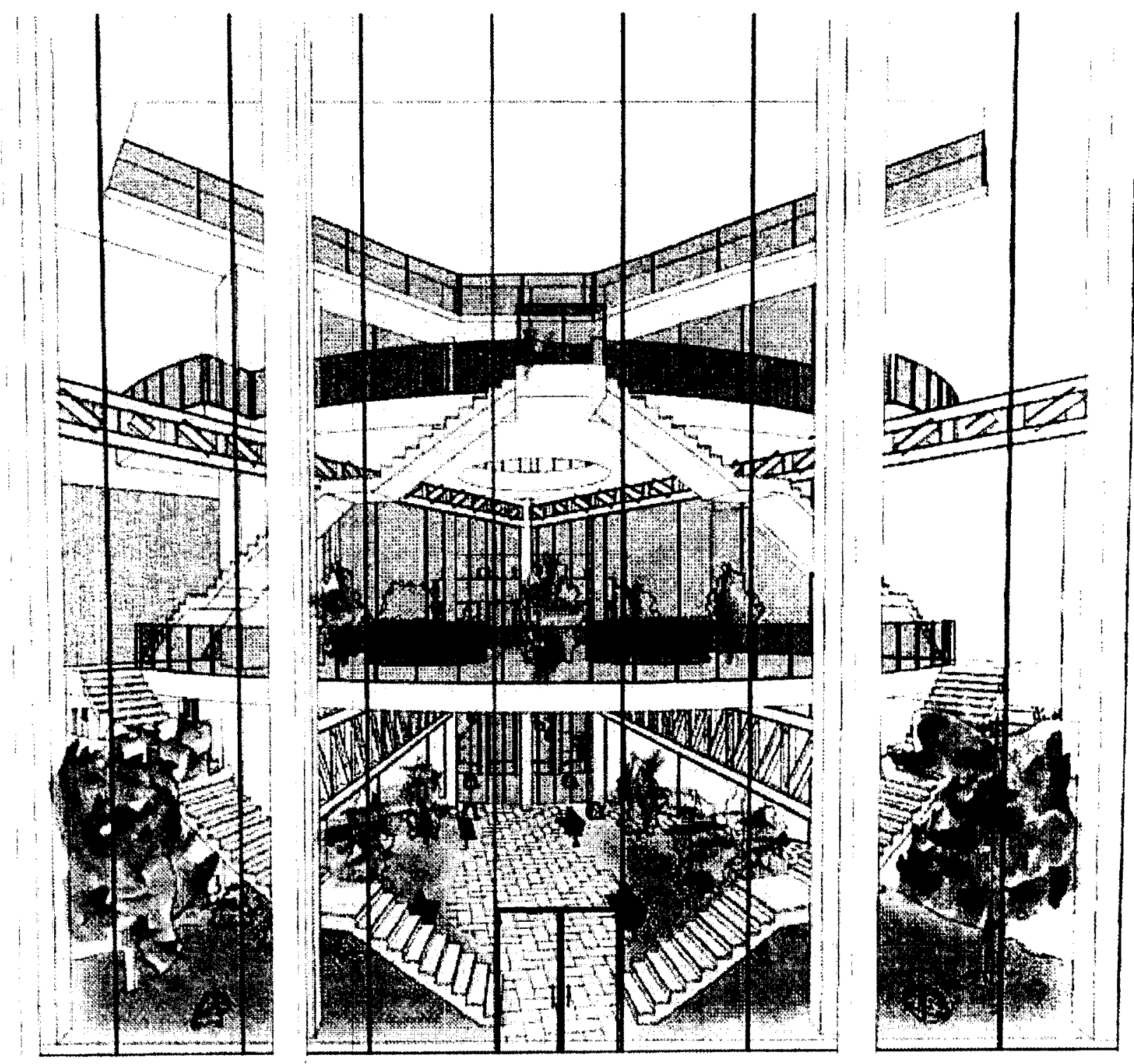
Figure 3

Scale: 1:150

The Atrium First Floor Plan

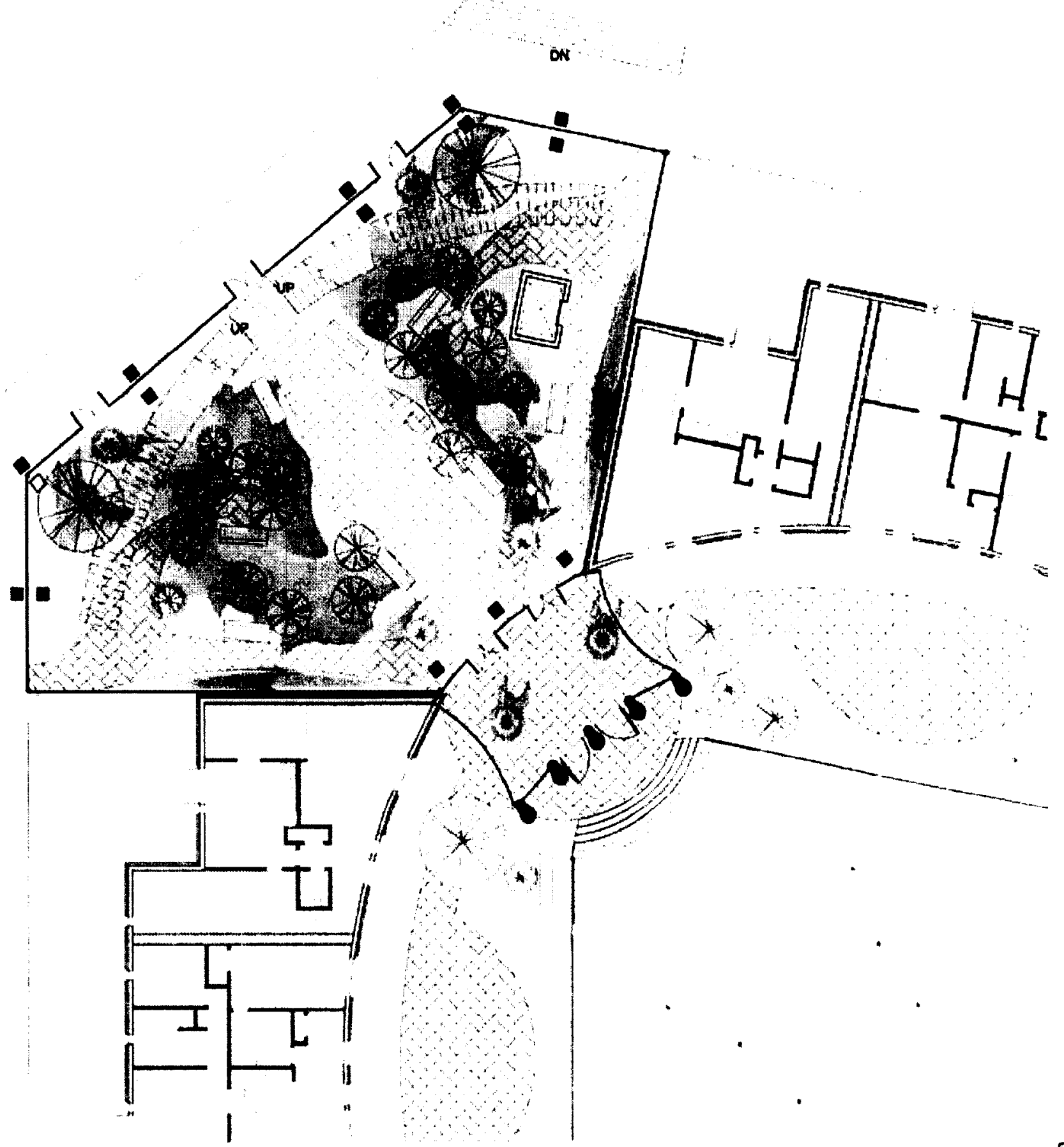


Figure 4

Scale: 1:150

The Atrium Second Floor

Plan

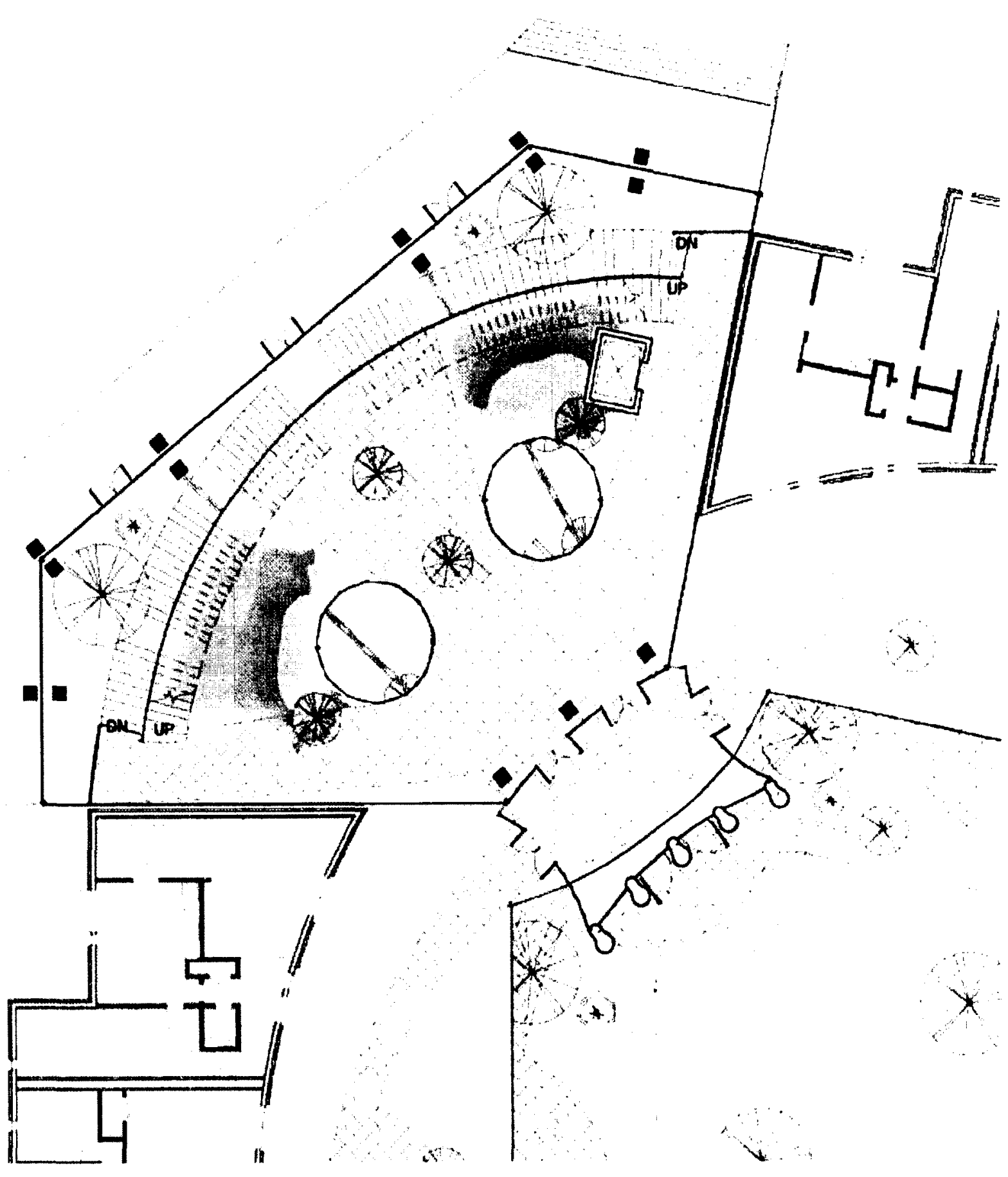


Figure 5

Scale: 1:150

The Atrium Third Floor Plan

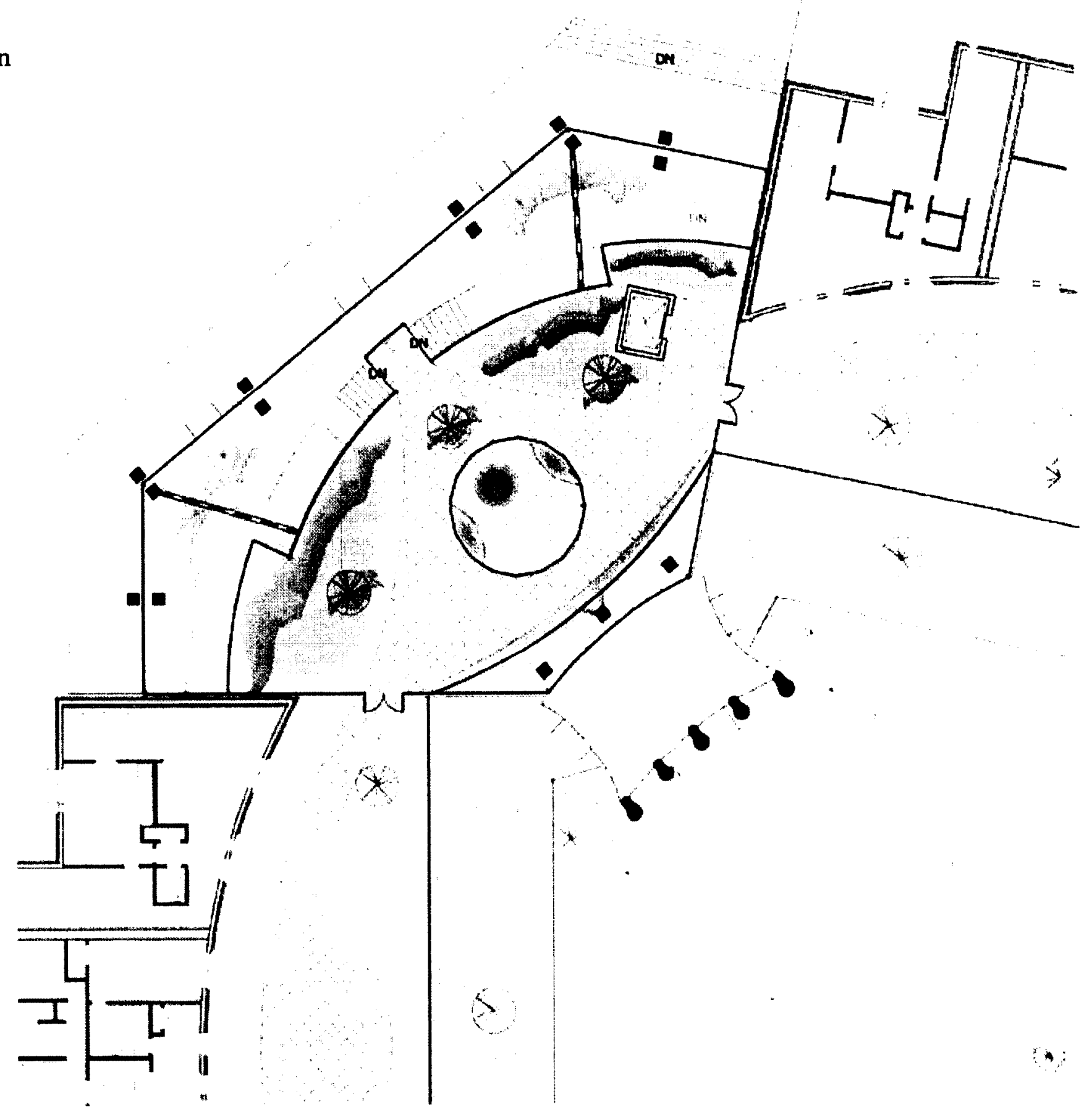


Figure 6

Scale: 1:150

First Floor Plan

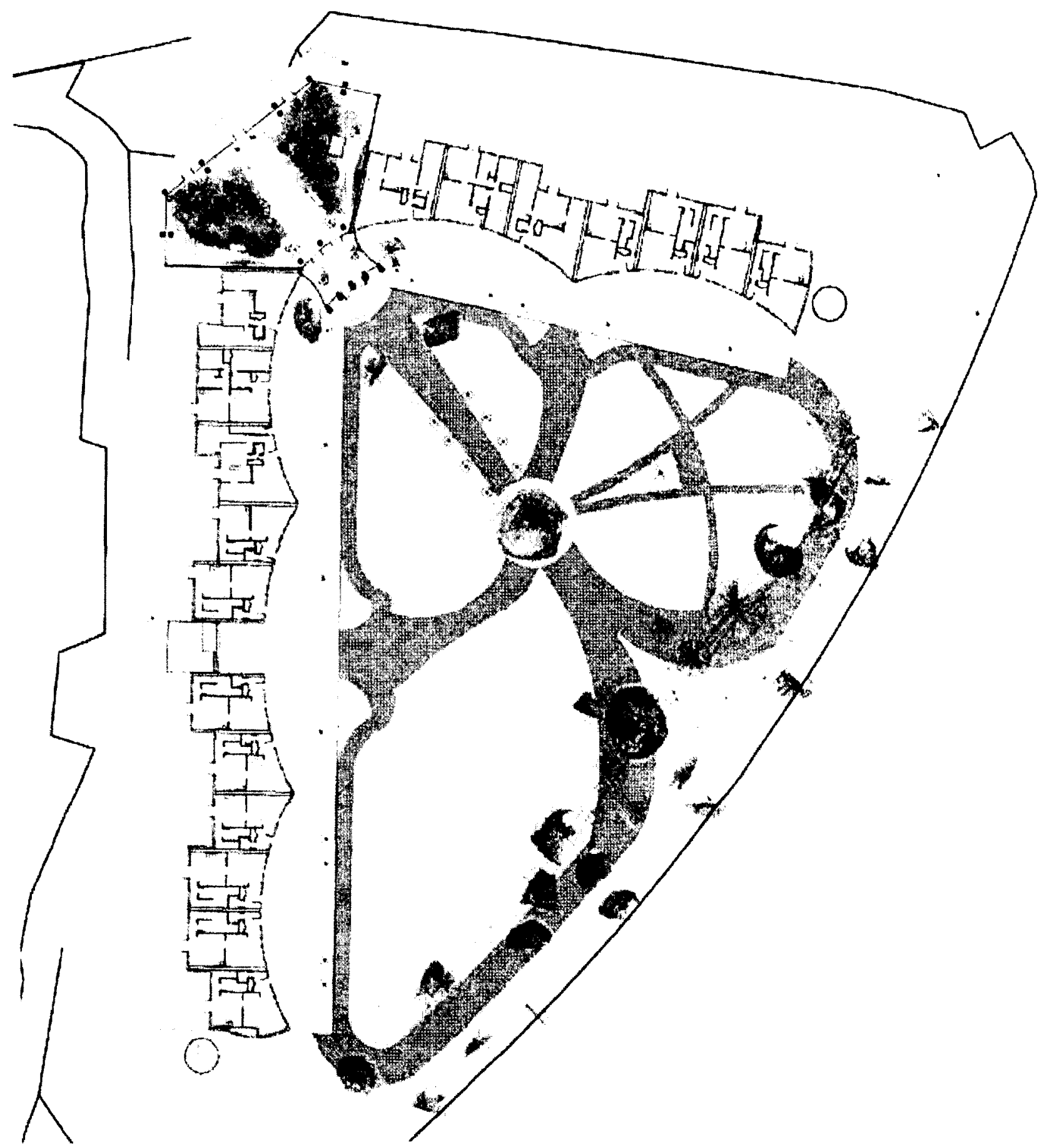


Figure 7

Scale: 1:150

Second Floor Plan
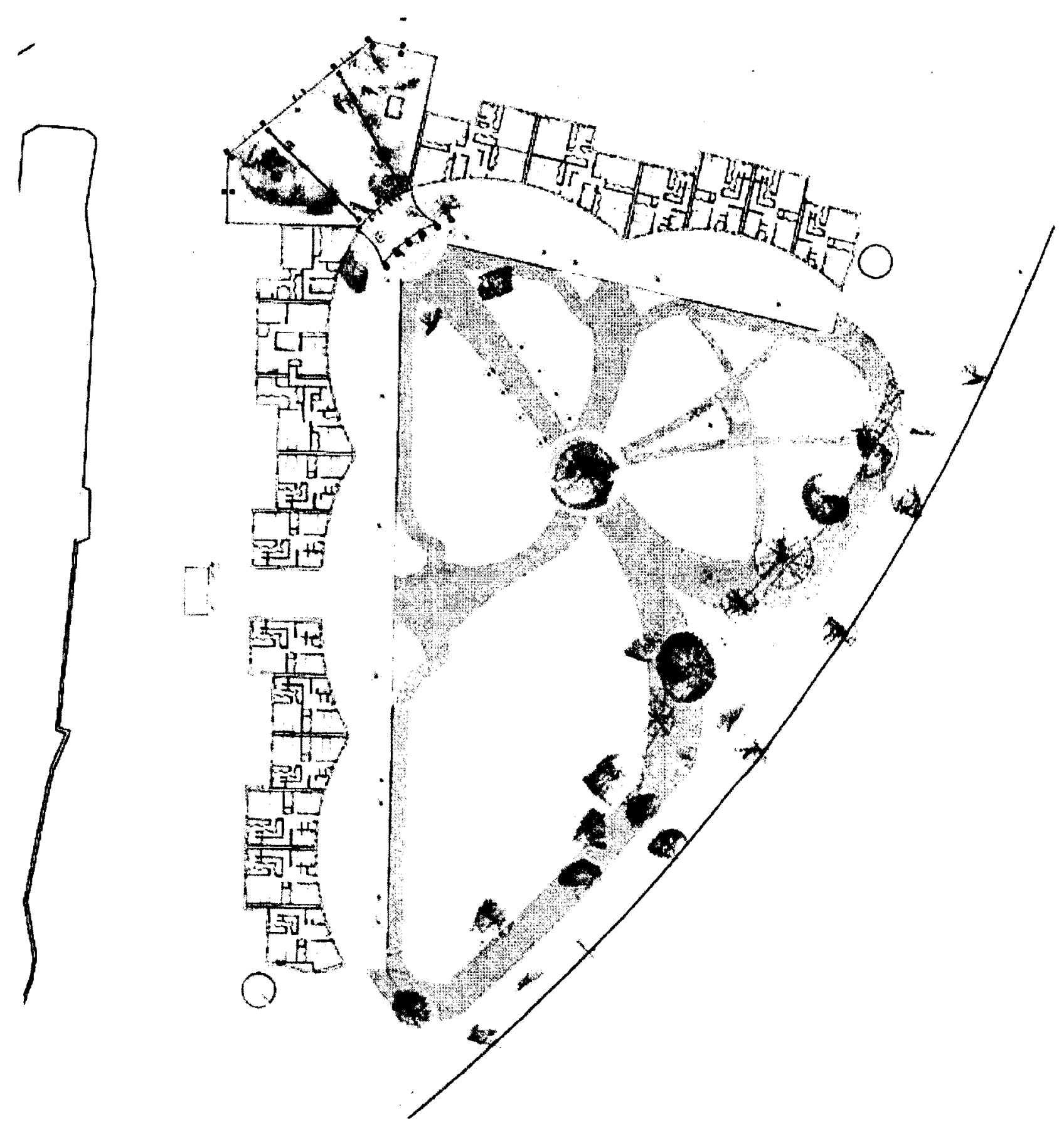
Figure 8

Scale: 1:150

Unit Floor Plan

This diagram indicates the hierarchy of rooms as they move from semi-private which would start at the entrance of the unit (yellow) through to the green. At the edge of the green is the beginning of the private area, (light red) and moves upstairs to the bedrooms which are red. The dark red signify that only family or special guests would be invited here.

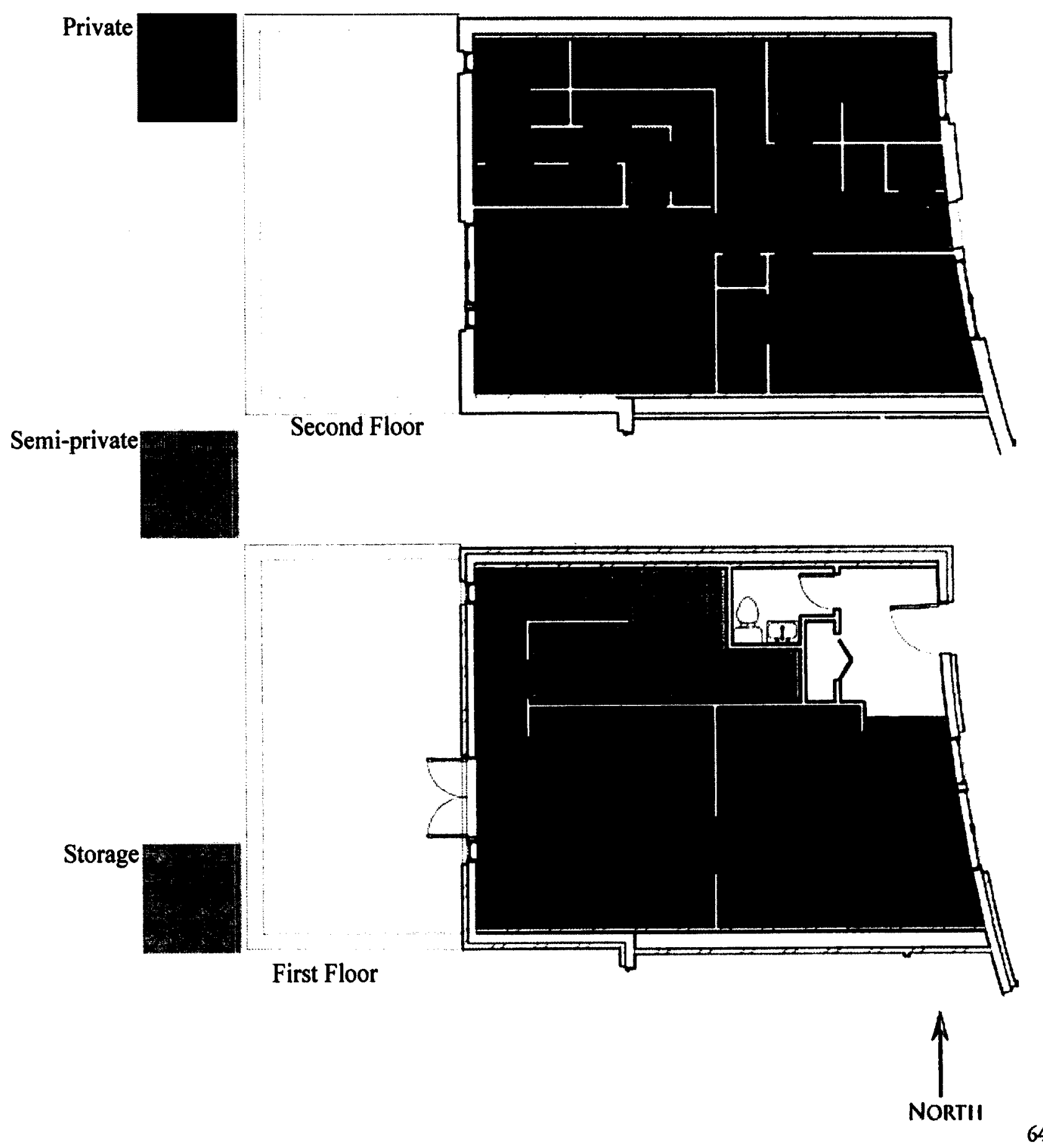


Figure 9

Scale: 1:50

Interior

This view is of the top floor and displays the back of a unit. The walls have been removed to display the inside. Visible is the kitchen, entrance to the storage area and the stairs leading up to the second floor. On the second floor the master

bedroom and ensuite are showing. 
Figure 10

Scale: 1:150

Exploded axio.

Showing floors 1822

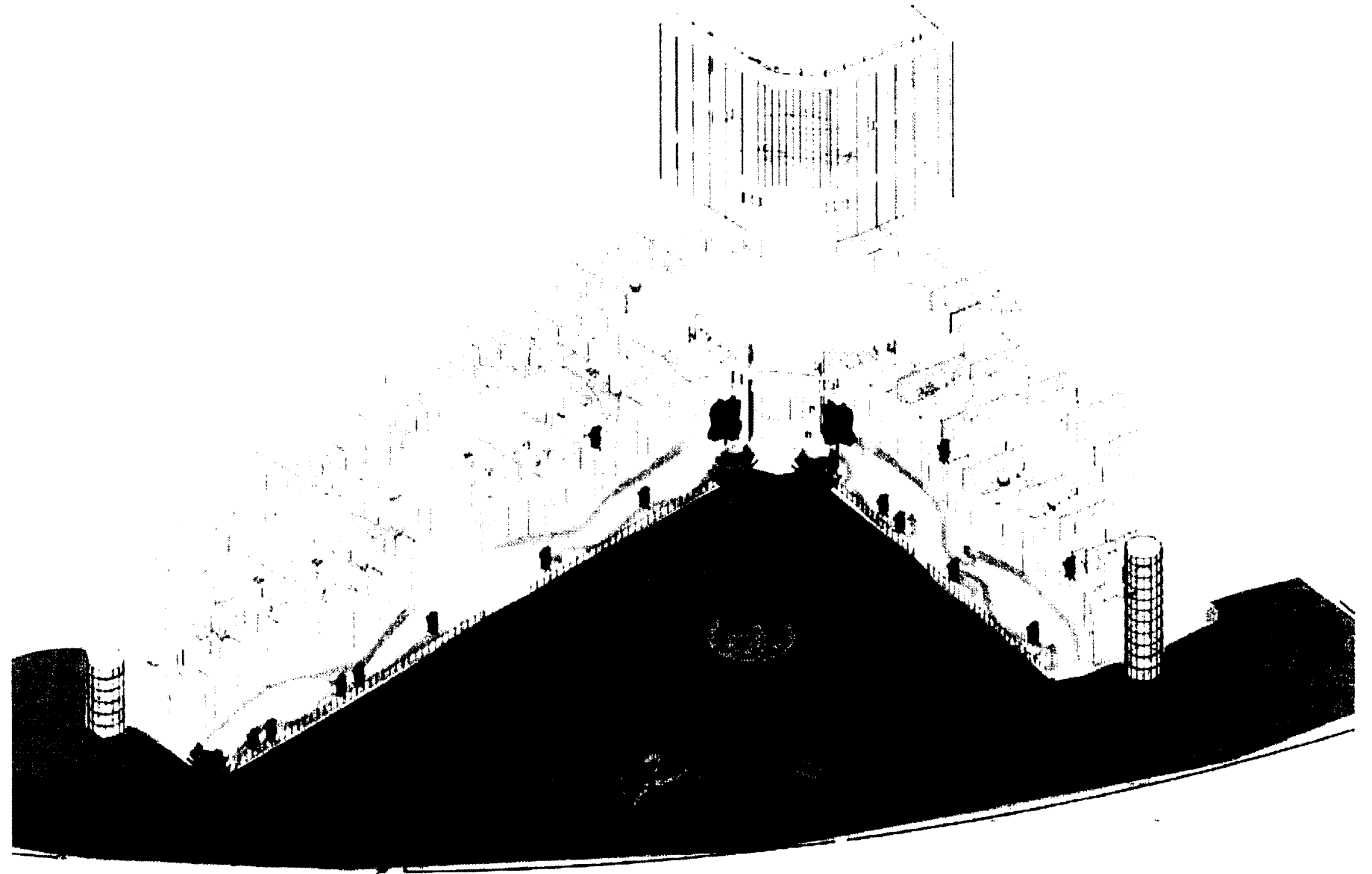


Figure 11

Scale: 1:150

Longitudinal Sections

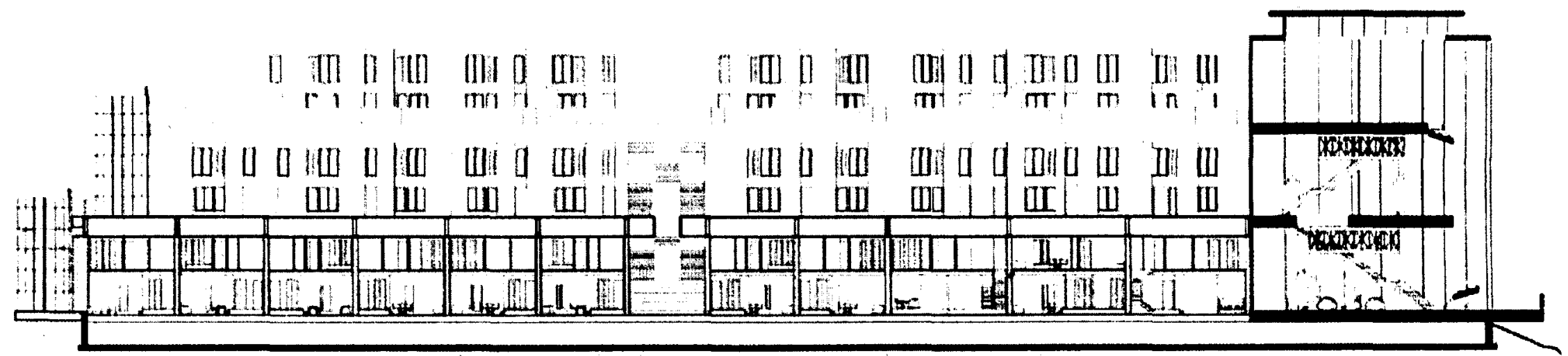

North - south section cut looking west

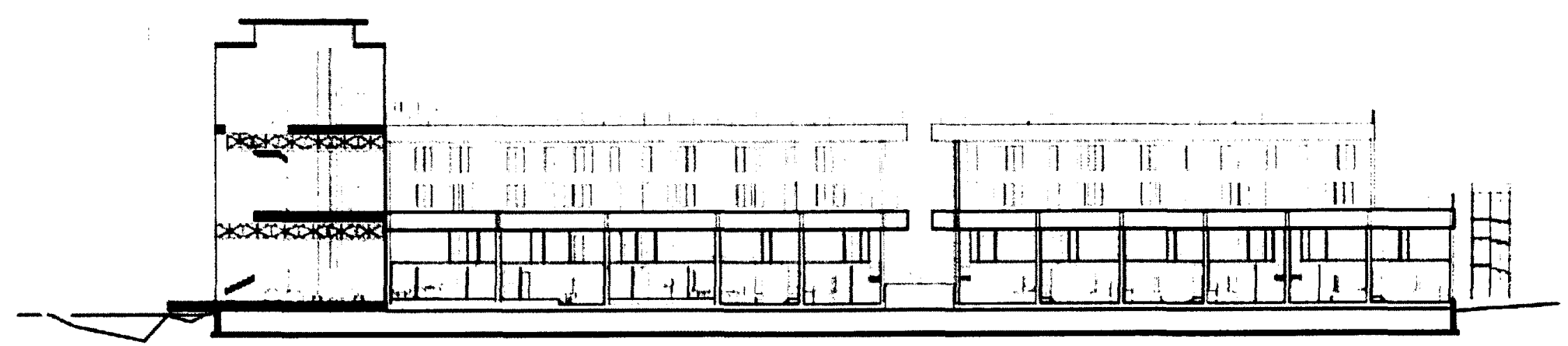

North - south section cut looking east 
Figure 12

Scale: $1: 150$

Section

Section: north - south wing; looking north.

Trees have been revoved for clarity.

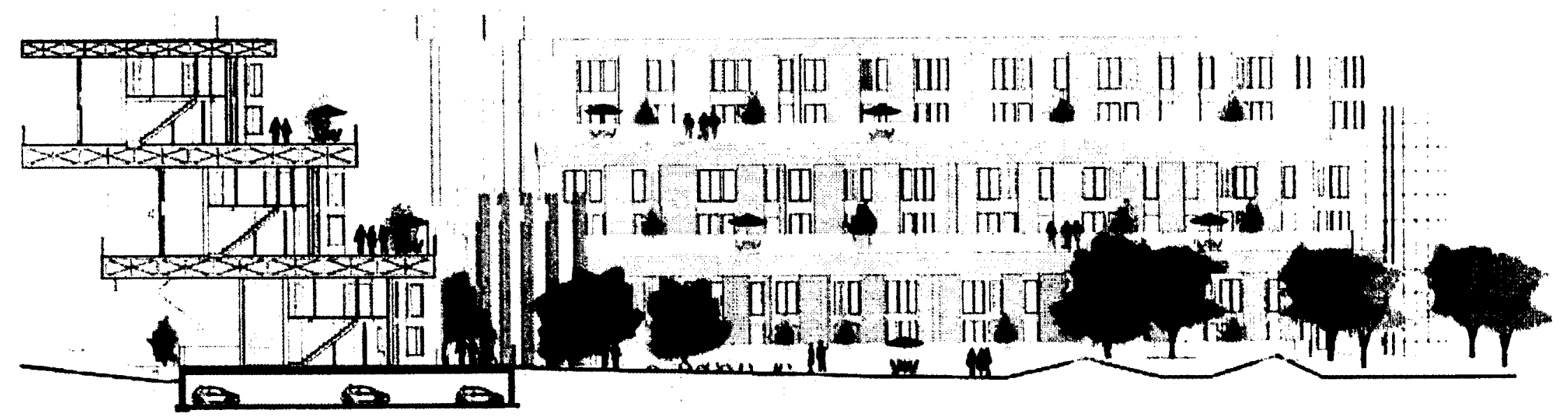


Figure 13

Scale: 1:50

Model

This model section represents the end of the

east-west wing of the propased residential

building. The terraces are clearly evident

showing the garden and path area. The exterior

walls have been removed from the unit on the

top floor to expose the interior. In this image

the living room on the main floor is visible

and is the second bedroom on the second

floor. Towards the back the kitchen and master

bedroom above it are visible.

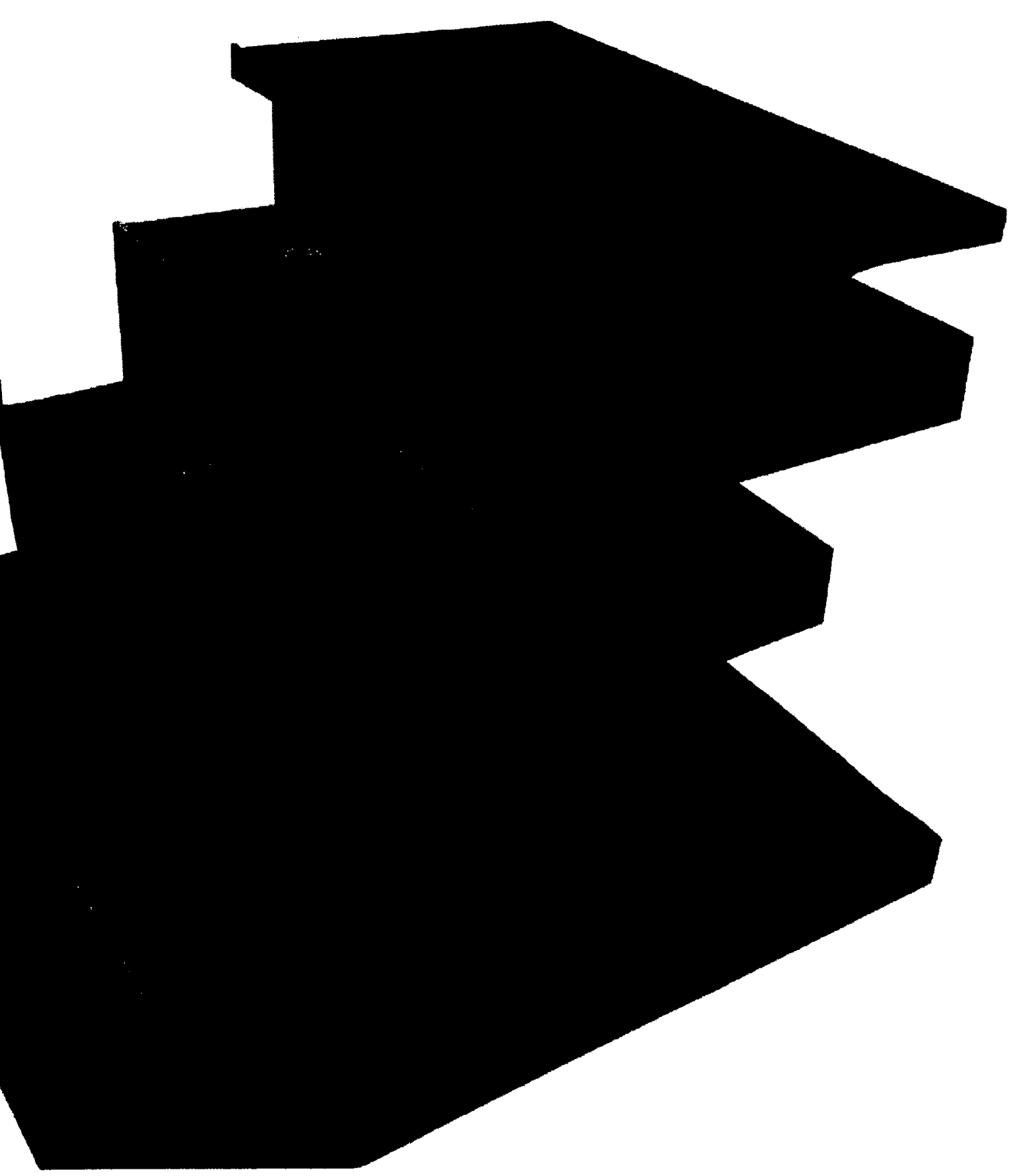


Figure 14

Scale: 1:150

Elevation One

North-south wing elevation. Looking cast.

(The back of the wing)

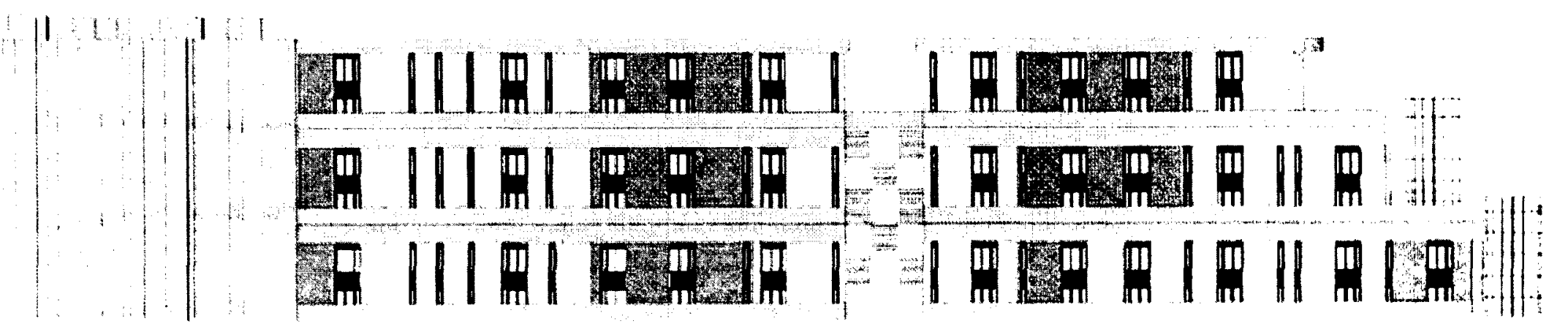


Elevation Two

East- west wing elevation. Looking north

(Many of the trees in the Garden are removed

for clarity)

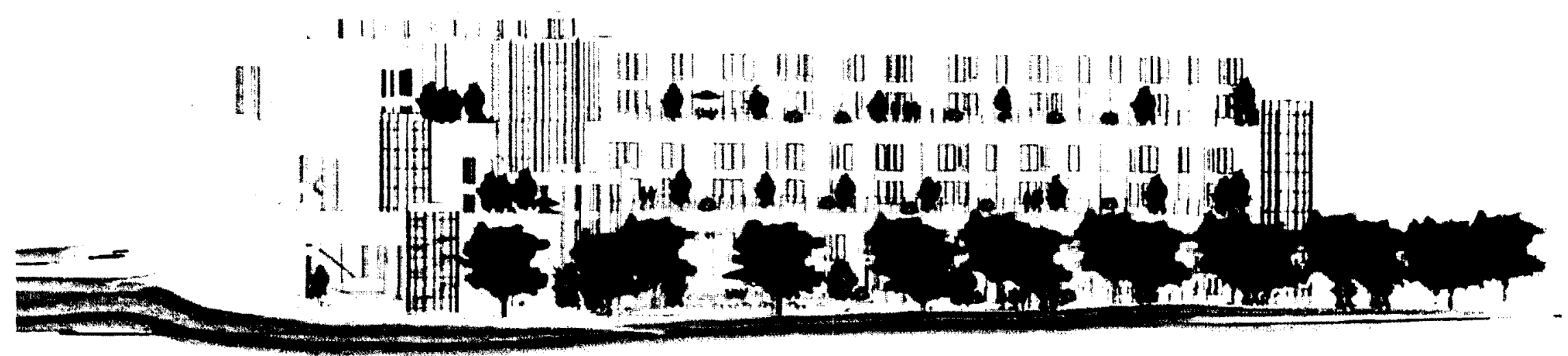




\section{Bibliography}

Ackerman, James. Palladio's Villas. Locust Valley, New York : JJ Augustin, 1967.

Ackerman, James A., The Villa. London: Thames and Hudson, 1990.

Bingham, Sarah et.al. Hurdman Station: Area Redevelopment Study. Kingston, ON: School of Urban and Regional Planning, Queens University, 2011

Boucher, Bruce. Andrea Palladio, The Architecture in His Time. New York: Abbeville Press, 2007.

Briggs, Asa. "From O’Brian to Haut-Brion" Illustrated London News, n. 278 summer (1990) p84-86.

Bronson, Gail. "In Advertising, Big Names Mean Big Money." U.S. News \& World Report, vol 95 n.1, 1983, p48.

Dethier Jean, ed. Chateaux Bordeaux, London: Mitchell Beazley, 1989.

Evers, F. Alton. The Master Handbook of Acoustics. Blue Ridge Summit, PA. Tab Books Inc, 1989.

Ferrand, Franck and Jean-Paul Kauffman. Bordeaux Chateaux: a History of the Grands Crus Classes 1855-2005, Paris: Flammarion, 2004.

Frascari, Marco. Honestamente Bella, Alvise Cornaro's Architectural views of Lady Architecture and her Maids Phronesis and Sophrosine, Montreal: McGill University 2007 Presented at the "Reconciling Poetics and Ethics in Architecture" conference, McGill University, Sept 15, 2007.

Graves, Michael. "Close Pegase Winery and Residence," Architectural Design, v 55 n l-2 (1985) p 11-14. 
Gazda, Elaine K., ed. The Villa of the Mysteries in Pompeii: Ancient Ritual, Modern Muse, Ann Arbor : Kelsey Museum of Archaeology and the University of Michigan Museum of Art, 2000.

Hamilton Gordon. "Consumers 'Deceived' by Low-cost Imports Being Sold as B.C. Wines.” The Vancouver Sun, Vancouver, B.C. Sept. 19, 2009, Section H, p1.

Holberton, Paul. Palladio's Villas. London: John Murray, Publishers, 1990

Holl, Steve. Intertwining. New York: Princeton Architectural Press, 1996.

Holl, Steve, Juhani Pallasmaa \& Alberto Perez-Comez. Questions of Perception, Phenomenology of Architecture. San Francisco: William Stout, 2006.

Hubler, Shawn. "Robert Mondavi, 1913-2008" Los Angeles Times. May 18, 2008.

Kuzmany, Marion and Kerstin Gust. "Wine and its path to architecture." A + U: architecture and urbanism, v 457, (2008) p. 50-55.

Leach Neal ed. Rethinking Architecture. New York: Rutledge, 1997.

Mallgrave, Harry F. and David Goodman. An Introduction to Architectural Theory. West Sussex, UK: Wiley \&Sons, 2011.

McMinn John. "Jackson-Triggs Estate Winery" Canadian Architect January (2003) p14-18.

Norberg-Schultz, Christian. "Michael Graves and the Language of Architecture", Buildings and Projects 1882-1989, New York: Princton Architectural Press, 1995. 
Palladio, Andrea. The Four Books of Architecture. Translated by Robert Tavernor and Richard Schofield. MIT press Cambridge Mass. 1997.

Phillips, Rod. A Short History of Wine. Harmondsworth: Penguin Books ltd, 2000.

Pearman, Hugh. "Wineries Hit the Architectural Big Time" The World of Fine Wine v 9 (2005) p. 89-91.

Polo, Marco. "In Vino Veritas," Canadian Architect October (2001) p20-23.

Shrady, Nicholas. "Napa's new vintage: Javier Barba brings life to Stag's Leap Wine Cellars" Architectural Digest. Vol.60, n.6, (2003) p.120,122,124.

Tavernor, Robert. Palladio and Palladianism. London: Thames and Hudson, 1991.

Tomkins, Calvin. Living Well is the Best Revenge. New York: the Viking press, 1962.

Walker, Harry and Olive. Carleton Saga. Ottawa, ON: Carleton county council, 1968.

Webb, Michael. Adventurous Wine Architecture. Victoria, Australia: The Images Publishing Group Pty. Ltd., 2005.

Webb, Michael. "Wine and architecture." A + U: architecture and urbanism, v 457, (2008) p.10-11.

Woodbridge, Sally. “An Unfinished Harvest," Progressive Architecture. v69 n2 (1988) p82-89. 